\title{
Assessing the Resilience of Agricultural Reservoirs in Ungauged Catchments under Climate Change Using a Ratio Correction Factors-Based Calibration and Run Theory
}

\author{
Sang-Hyun Lee ${ }^{1}\left(\mathbb{D}\right.$, Sungtae Shin ${ }^{2} \mathbb{D}$, Jin-Yong Choi ${ }^{3}$, Jihoon Park ${ }^{4}\left(\mathbb{D}\right.$ and Seung-Hwan Yoo ${ }^{5, *}$ \\ 1 Research Institute for Humanity and Nature, Kyoto 603-8047, Japan; sanghyunsnu@gmail.com \\ 2 Department of Mechanical Engineering, Dong-A University, Busan 49315, Korea; stshin@dau.ac.kr \\ 3 Department of Rural Systems Engineering, Research Institute for Agriculture \& Life Sciences, and GBST, \\ Seoul National University, Seoul 08826, Korea; iamchoi@snu.ac.kr \\ 4 Climate Services and Research Division, APEC Climate Center, Busan 48093, Korea; gtjihoon@apcc21.org \\ 5 Department of Rural and Bio-systems Engineering, Chonnam National University, Gwangju 61186, Korea \\ * Correspondence: yoosh15@chonnam.ac.kr; Tel.: +82-62-530-5182; Fax: +82-62-530-2159
}

Received: 10 May 2020; Accepted: 5 June 2020; Published: 6 June 2020

check for updates

\begin{abstract}
This study applied ratio correction factor (RCF) optimization to calibrate the daily storage of agricultural reservoirs located in ungauged catchments that lack stream flow data. Using Run theory, we then assessed the impacts of climate change on the resilience of agricultural reservoir operations during reservoir drought conditions. First, we optimized the RCFs of inflow and outflow in three agricultural reservoirs in Korea using limited measurement data from 2008 to 2017; the results showed high performance regarding the simulation of daily reservoir storage. Second, we simulated daily storage volume in reservoirs from 2018 to 2099, using future climate change data, and analyzed the duration and intensity of reservoir drought conditions, which indicated that the storage capacity is under the critical value. Without calibration, the correlation between the simulated and measured reservoir water volumes was very low, but the correlation increased after calibration of the simulated water volumes. A linear relationship between the simulated and measured volumes was observed with a correlation coefficient value of 0.9 , indicating that the simulated reservoir values after calibration closely match the measured values. In addition, the maximum intensity of reservoir drought in the Kicheon reservoir was determined to be $486,000 \mathrm{~m}^{3}$ before calibration but $506,000 \mathrm{~m}^{3}$ after calibration. The duration results showed that long-term reservoir drought conditions will be observed more often in the future owing to climate change, and this could be a negative factor affecting the resilience of reservoir operations.
\end{abstract}

Keywords: agricultural reservoir; calibration; ratio correction factor; resilience; climate change

\section{Introduction}

The main objectives or strategies of water management are to enable supply of freshwater at the appropriate time and place. Some of the documented hydrological changes associated with global climate change include changes in precipitation patterns, rising surface temperature, and increases in the frequency and intensity of floods and droughts [1]. The increased frequency of heavy rainfall events particularly undermines the reliability of rain as a source of irrigation water, thereby increasing the importance of finding a more secure supply of irrigation water to ensure food security.

To address this issue, many studies have recently been conducted to investigate changes in irrigation water requirements under climate change conditions. The vulnerability of water resource 
systems, such as reservoirs, to climate change will only increase, and this aspect should be considered from a holistic perspective; thus, flood control, drought resilience, ecological flow, and the various demands for water in a given area should be taken into account. Accordingly, the evaluation of climate change impact on agricultural reservoirs has been identified as a critical research topic because of the need to ensure an adequate supply of irrigation water, and many studies have been conducted on this topic.

The reliability, resilience, and vulnerability of a multipurpose storage reservoir were evaluated using statistical analysis, Monte-Carlo simulations, and the Vulnerability-Resilience Indicator Prototype [2,3]. Fallah-Mehdipour et al. (2020) showed the positive impacts of an integrated climate-environment-water approach for reservoir operation in comparison to the impacts of a non-integrated one [4], and Shiau et al. (2018) analyzed the frequency of water deficiency in Taiwan and proposed hedging rules for reservoir operation to meet water demands during droughts [5]. Using the Soil and Water Assessment Tool model, climate change impacts on hydrology, soil erosion, nutrient cycling, and the effectiveness of best management practices were quantified at the watershed scale, and they showed that the increasing frequency of rainfall events may decrease the efficiency of watershed management in the future [6]. Studies on the impacts of climate change on reservoirs, including multi-reservoir systems, have also been conducted. For example, the climate change impacts on the Yakima River reservoir system, which supplies water to $\sim 180,000$ irrigated hectares via the operation of five reservoirs, have been assessed [7]. An optimization approach has been applied to assess the operation of multiple reservoirs, including both existing and planned hydropower reservoirs in the transboundary Mekong River [8]. In terms of field-scale studies relating to reservoir operation, Mhagama (2020) examined the manner in which irrigation farming schemes were exposed to the adverse effects of climate change variability and found that farmers have been changing their farming practices, including soil and water conservation practices and changes in cropping patterns, to overcome drought conditions [9].

The precise simulation of water storage is critical to obtain an accurate evaluation of climate change impacts. Traditionally, calibration has been one of the important methods employed in the hydrological field. Bomhof et al. (2019) investigated calibration techniques in the Lake of the Woods-Rainy Lake watershed and revealed that the multi-objective formulation can generate quality results equivalent to those generated via the weighted single objective approach [10]. Sleziak et al. (2019) addressed the uncertainties related to the choice of calibration/validation periods for long data sets under varying climatic input conditions [11]. They found that the model performance decreased during the calibration period, while it increased during the validation period with the increase in number of years available for calibration.

Agricultural reservoirs are typically small in scale and usually located in mountainous regions where catchments are ungauged, which makes it difficult to calibrate the simulated water volume entering the reservoirs. Therefore, the estimation of water inflow to the reservoirs from catchment runoff remains a challenge. The measurement of water outflow is also difficult, as water is withdrawn from the reservoirs through water channels. Ultrasonic water meters have been installed in water channels in some reservoirs, and further research is currently being conducted to analyze the noise they produce in the data. Although the water volume in reservoirs is continuously monitored, water storage volume simulations are dependent on theoretical water inflow and outflow models, and typically only the measured volume of water stored can be used to calibrate reservoir simulations. In summary, there is a lack of research on the calibration of simulated agricultural reservoirs owing to limited water volume measurement data. Meanwhile, water budget models that only consider simple variables with which to decrease uncertainty are being applied in simulations.

In addition, the evaluation of reservoir functioning under climate change has been mostly conducted via assessments of the maximum volume of water required per year, or by focusing on specific weather events (such as droughts) via analysis of the shortage of stored water during drought periods [12,13]. Yoo et al. (2013) assessed climate change impacts on the water storage of agricultural 
reservoirs using the reservoir water-balance model, in which data pertaining to climate change as well as changes during the paddy rice growing period and land use were considered [14]. In particular, achieving better operational procedures in water facilities such as reservoirs and dams is an increasingly important issue, and the development of sensing technology and the use of big data could promote this. Lee et al. (2006) developed a water supply capacity index to monitor droughts in a reservoir [15], and Nam et al. (2012) assessed the vulnerability of the water supply to an agricultural reservoir in Korea via probability distribution and reliability analysis methods [16].

However, to evaluate the long-term stability of agricultural reservoirs, it is necessary to understand the speed at which reservoirs can recover from a vulnerable state to their normal functioning state. Since reservoirs are water storage facilities, research on reservoir resilience through water volume recovery is as important as research on the shortage of reservoir water; yet, research on the connection between reservoir resilience and climate change is still lacking. In addition, the impacts of climate change on irrigation water supply intensify with time, with a rise in extreme rainfall frequency and negative crop productivity caused by rising temperature being increasingly reported [17-21].

Accordingly, studies that aim to enhance the accuracy of reservoir water volume simulation are required to facilitate a reliable supply of irrigation water through the operation of reservoirs in response to climate change. The simulated water volume in a reservoir is determined on the basis of the difference between the inflow and outflow of water. In the case of reservoirs that serve multiple functions, such as supplying water for multiple stakeholders as well as generating electrical power, a model that considers diverse variables is required. A detailed model is required as there is significant water inflow to reservoirs through catchment runoff, particularly when the runoff from several smalland medium-scale catchments is combined simultaneously. For water outflow, a model optimized for water withdrawal from the reservoirs for different purposes may be required. Therefore, diverse studies have been conducted on large-scale reservoirs that serve multiple functions.

In Korea, approximately $80 \%$ of the paddy fields in Korea are irrigated, drawing water from over 63,000 agricultural water structures. Reservoirs are the main water sources, although others, including pumping stations and head works, provide approximately half the supply. A huge amount of the irrigation water required for paddy rice fields is supplied from approximately 17,400 agricultural reservoirs in Korea [22]. As agricultural reservoirs contribute to the production of rice, which is a critical crop in terms of food security, any negative effect of climate change on the stability of the reservoirs has a direct impact on food security. Accordingly, simulations of reservoir capacity in response to future climate change is necessary for securing a stable food supply.

This study aims to develop a calibration method for optimizing the simulation of reservoirs in ungauged catchments (which indicates the lack of observed runoff data), and to analyze the resilience of agricultural reservoir operations under climate change. First, we applied ratio correction factors (RCFs) to the inflow and outflow of agricultural reservoirs simulated using existing models, such as the Tank model and the water balance model, and optimized the RCFs by comparing simulated and observed daily storage volumes. Second, future meteorological projection data under climate change were used to simulate the water volume of the three reservoirs from 2018 to 2099, and then analyzed the duration, intensity, and magnitude of the water volume required for recovery above the threshold volume for assessing resilience of reservoirs.

\section{Materials and Methods}

The key points of this study are to apply RCF calibration to the simulation of a reservoir in ungauged catchments and to assess the climate change impacts on reservoir droughts identified by intensity and duration of water requirement for recovery. Figure 1 shows a flowchart of this methodology. First, we applied the various data of climate, crop, and reservoir to the runoff and irrigation simulation models. Second, the results of models were adapted to the water balance model for simulating reservoir storages. After that, we applied the monthly RCFs to calibrate the simulation and validated the RCFs' applicability through the observed data of reservoir storages from 2008 to 2017. 
Finally, we identified the reservoir droughts using the concept of "water requirement for recovery" and analyzed the intensity and duration of reservoir droughts in future seasons under a climate change scenario using Run theory.

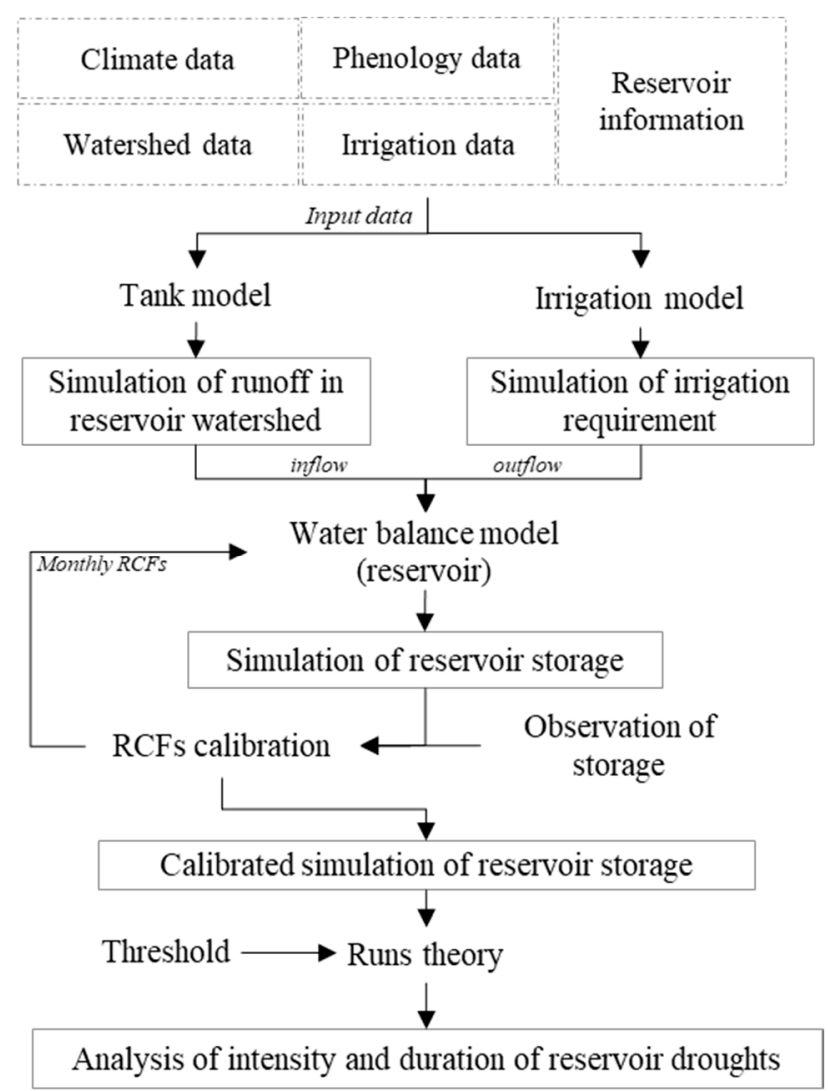

Figure 1. A flowchart of adapting RCF (ratio correction factor) calibration and assessing climate change impacts on reservoir droughts.

\subsection{Temporal Simulation of Reservoir Storage Based on Reservoir Water Balance Model}

\subsubsection{Water Balance Model for Simulating Daily Storage Volume in Agricultural Reservoirs}

The concept of water balance was applied for the simulation of agricultural reservoirs. Water balance typically considers the changes in water storage volume caused by inflow and outflow, while the total volume within the system remains constant. Thus, during simulations, the volume of water in a reservoir on a certain day is simulated by calculating the water balance using the reservoir water volume of the previous day and the reservoir inflow and outflow on the simulated day. In other words, the inflow from the catchment runoff and the direct input as a result of precipitation are the positive components, and irrigation water withdrawal, overflow at the sluice gates, evaporation losses, and other losses such as percolation and dam seepage are the negative components. When the simulation results pertain to a volume of water larger than the maximum capacity of the reservoir, the excess becomes spillage released through spillways, and the volume of the reservoir is set as the maximum capacity of the reservoir. Contrastingly, when the simulation results represent a volume of water below the withdrawn volume, discharge is not possible, and the reservoir volume is set as the volume of the water withdrawn.

Because simulating the volume of the reservoir through the application of water balance involves only a few variables, this process is well suited to simulations of small- to medium-scale agricultural reservoirs, of which the main function is irrigation water supply. Therefore, the simulation of reservoir water volume using water balance is widely applied in agricultural reservoir research in 
Korea. The Korea Rural Community Corporation, which oversees the operation and management of Korean agricultural reservoirs, has also developed a daily reservoir water volume simulation model for application.

The central component of the agricultural reservoir water balance model is the simulation of the volume of inflow and outflow. As most agricultural reservoirs in Korea are located in mountainous areas, inflow is mainly derived from rainfall runoff in ungauged catchments. In addition, agricultural reservoirs mainly serve the purpose of water supply to rice paddies. Irrigation water supply is thus considered the most essential component in terms of outflow in the water balance model. In summary, the water balance model simulates the changes in storage in an agricultural reservoir, and it is composed of two modules. The first module estimates inflow to the reservoir from the watershed, and the second module is the irrigation model which determines the amount of water released from the reservoir, as shown in Equation (1),

$$
\begin{gathered}
\mathrm{S}_{\mathrm{t}}=\mathrm{S}_{\mathrm{t}-1}+\mathrm{IF}_{\mathrm{t}}+\mathrm{RF}_{\mathrm{t}}-\left(\mathrm{RL}_{\mathrm{t}}-\mathrm{RO}_{\mathrm{t}}-\mathrm{RE}_{\mathrm{t}}\right) \\
\mathrm{S}_{\mathrm{t}}=\mathrm{S}_{\max } \text { for } \mathrm{S}_{\mathrm{t}} \geq \mathrm{S}_{\max } \\
\mathrm{S}_{\mathrm{t}}=\mathrm{S}_{\min } \text { for } \mathrm{S}_{\mathrm{t}} \leq \mathrm{S}_{\max }
\end{gathered}
$$

where $t$ is time $(d)$, ST is reservoir storage $\left(\mathrm{m}^{3}\right)$, IF is the inflow $\left(\mathrm{m}^{3}\right), \operatorname{RF}$ is the rainfall $\left(\mathrm{m}^{3}\right), \mathrm{RL}$ is the released water supply used for agricultural irrigation $\left(\mathrm{m}^{3}\right), \mathrm{RO}$ is the overflow at the sluice gates $\left(\mathrm{m}^{3}\right)$, and RE is evaporation loss $\left(\mathrm{m}^{3}\right)$.

\subsubsection{Simulation of Rainfall Runoff in an Ungauged Catchment Using the Tank Model}

In lumped conceptual hydrological modeling, a watershed is sometimes represented by a series of storage units, reservoirs, or tanks that can retain precipitation and release water to their outlets, so that the delay and attenuation of runoff can be simulated [23]. For modeling the rainfall runoff process, models have been developed that are based on conceptual representations of the physical processes of the water flow lumper over the entire catchment area, for example the Sacramento model [24], the Tank model [25], the HBV model [26], and the MIKE 11/NAM model [27,28].

To simulate runoff in agricultural reservoirs, we applied the Tank model, which has been commonly used in watershed assessment and planning, including for a data-scarce watershed in Korea. The Tank model employed in this study consists of three tanks. Water running out of the side outlets of the tanks represents the surface runoff (for the first or top tank), the intermediate runoff (for the second tank), and the base flow (for the bottom tank) [29,30]. For example, the side outlets of the tanks are used for the calculation of runoff from the same tank, and the bottom outlets are used for the calculation of the infiltration (from the same tank). Precipitation is added in the top tank, and evaporation is subtracted from the top tank onwards. The output from the top tank is considered the surface runoff, while the output from the second runoff is considered as the intermediate runoff. Output from the second tank is considered the sub-base runoff and the output from the bottom tank is considered as the base flow.

This model is very simple, but the output behavior is not as simple and can represent many types of hydrographs in an area of mixed land use, including paddy fields. Therefore, various applications of the Tank model have been used to simulate runoff in humid areas, particularly in Asian countries [31-34]. For example, Kuok et al. (2011) analyzed the appropriate number of tanks that should be used in the Tank model for accurate simulation of runoff from a rural catchment in a humid region [33]. In addition, the Tank model was applied in various fields. For example it was used for simulating the flow in paddy fields in a low-lying, flat area [35-37], analyzing runoff and infiltration on sub-watersheds in the Lalindu river in Indonesia recently [38], and simulating the fluctuation of the groundwater level at an observation well in Kumamoto, Japan [39]. 


\subsubsection{Estimation of Irrigation Water Requirement in Paddy Rice Fields}

Supply of irrigation water is the most important function of agricultural reservoirs in Korea. Generally, the volume of irrigation water required is determined via crop evapotranspiration and soil water content mainly saved from rainfall. Thus, the gap between crop evapotranspiration and soil water is supplied as irrigation water from water facilities such as a pumping stations and reservoirs. The irrigation water requirement is dependent on the crop because of crop evapotranspiration, but the soil condition is also a critical factor. For example, because the soil in paddy fields has a low level of infiltration and a high level of rainfall runoff, the loss of soil water via crop evapotranspiration in paddy fields may be less than that in upland fields. However, transplantation of paddy rice, which is a widespread cultivation system in Asian countries such as Korea, Japan, and Vietnam, is performed in ponded paddies. The irrigation water requirement represents the amount of water required for maintaining the ponding water depth in paddy fields, and it is determined on the basis of the losses from crop evapotranspiration, daily ponding water depth, rainfall, and deep percolation, among other factors, as shown in Equation (2) [40],

$$
\mathrm{PWD}_{\mathrm{t}}=\mathrm{PWD}_{\mathrm{t}-1}-\mathrm{ET}_{\mathrm{ct}}-\mathrm{DP}_{\mathrm{t}}+\left(\mathrm{RF}_{\mathrm{t}}-\mathrm{SR}_{\mathrm{t}}\right)
$$

where $t$ is time (day), PWD is ponding water depth $(\mathrm{mm}), \mathrm{ETc}$ is crop evapotranspiration, SR is surface runoff in the paddy field outlet ( $\mathrm{mm}$ ), DP is deep percolation $(\mathrm{mm})$, and RF is rainfall $(\mathrm{mm})$. Most paddy rice irrigation systems in Korea were developed based on Korea's relatively homogenous soil, which is clay-textured and facilitates relatively low percolation rates [41]. The Rural Research Institute in Korea suggests that $5.0-5.6 \mathrm{~mm} /$ day of water percolates into paddy field soil, on the basis of field experiments conducted in several basins since 1970 [42].

Reference evapotranspiration (ETo) is an important factor for estimating crop growth, water demand, and crop water management [43]. Changes in the ETo are of great significance for water resource planning, irrigation requirements, and agricultural production $[44,45]$. The ETo was calculated using the Penman-Monteith equation [46], which allows the user to input necessary daily, weekly, and monthly atmospheric weather data (air temperature, humidity, radiation, and wind speed), as shown in Equation (3). The ETo can be multiplied by the crop coefficient $(\mathrm{Kc})$, which is a unique factor that takes plant properties into account to determine crop evapotranspiration (ETc), as suggested by Equation (4). Kc can be influenced by cultivation, local climatic conditions, and seasonal differences in crop growth patterns [47]. Accordingly, the localized Kc should be applied to calculate ETc and the water footprint. In Korea, Yoo et al. (2008) estimated Kc using the measured and simulated ETc [48].

$$
\begin{gathered}
\mathrm{ET}_{0}=\left\{0.408 \Delta\left(\mathrm{R}_{\mathrm{n}}-\mathrm{G}\right)+\gamma\left(900 T^{-1}+273\right) \mathrm{u}_{2}\left(\mathrm{e}_{\mathrm{s}}-\mathrm{e}_{\mathrm{a}}\right)\right\} \times\left\{\Delta+\gamma\left(1+0.34 \mathrm{u}_{2}\right)\right\}^{-1} \\
\mathrm{ET}_{\mathrm{c}}=\mathrm{ET}_{0} \times \mathrm{K}_{\mathrm{c}}
\end{gathered}
$$

where ETo is the reference crop evapotranspiration $(\mathrm{mm} / \mathrm{d})$, ETc is crop evapotranspiration $(\mathrm{mm} / \mathrm{d}), \mathrm{Kc}$ is the crop coefficient, $\Delta$ is the slope of the saturated vapor pressure/temperature curve $\left(\mathrm{kPa} /{ }^{\circ} \mathrm{C}\right), \gamma$ is the psychrometric constant $\left(\mathrm{kPa} /{ }^{\circ} \mathrm{C}\right), \mathrm{u}_{2}$ is the wind speed at a height of $2 \mathrm{~m}(\mathrm{~m} / \mathrm{s}), \mathrm{R}_{\mathrm{n}}$ is the total net radiation at the crop surface $\left(\mathrm{MJ} /\left[\mathrm{m}^{2} \cdot \mathrm{d}\right]\right), \mathrm{G}$ is the soil heat flux density $\left(\mathrm{MJ} /\left[\mathrm{m}^{2} \cdot \mathrm{d}\right]\right), \mathrm{T}$ is the mean daily air temperature at a height of $2 \mathrm{~m}\left({ }^{\circ} \mathrm{C}\right), \mathrm{e}_{\mathrm{s}}$ is the saturation vapor pressure $(\mathrm{kPa})$, and $\mathrm{e}_{\mathrm{a}}$ is the actual vapor pressure $(\mathrm{kPa})$.

In paddy fields with a ponding system, understanding optimal ponding water depth (OPWD) by growth stages is required to estimate the net irrigation water requirement (NIWR), which indicates the amount of water required for the OPWD to be met from current ponding water depth (PWD). The OPWD is assigned by growth stages. For example, transplanting water should be supplied to keep paddy fields saturated and to set the initial OPWD. In addition, transplanted water should be supplied to keep paddy fields saturated and to meet the initial pond water depth generally at around 
30 days, and the water requirement for the transplanting period is approximately $140 \mathrm{~mm}$ in depth in Korea [49]. After the transplanting season, the various OPWDs are applied by crop phenology [49,50].

In paddy rice fields, rainfall can directly contribute to PWD, which is represented by effective rainfall (ER). Generally, ER indicates the amount of rainfall that contributes to the water captured by the soil; however, in a paddy field cultivated using the ponding system, the soil is always saturated, and rainfall is directly subsumed into the pond water. On the basis of the ponding water system, the NIWR and ER in the water balance model are described as shown in Equation (5):

$$
\begin{gathered}
\mathrm{NIWR}_{\mathrm{t}}=\mathrm{OPWD}_{\mathrm{t}}-\mathrm{PWD}_{\mathrm{t}} \text { for } \mathrm{OPWD}_{\mathrm{t}}>\mathrm{PWD}_{\mathrm{t}} \\
\mathrm{NIWR}_{\mathrm{t}}=0 \text { for OPWD } \mathrm{OPWD}_{\mathrm{t}}<\mathrm{PW}_{\mathrm{t}} \\
\mathrm{ER}_{\mathrm{t}}=\mathrm{RF}_{\mathrm{t}}, \text { for } \mathrm{SR}_{\mathrm{t}}=0 \\
\mathrm{ER}_{\mathrm{t}}=\mathrm{RF}_{\mathrm{t}}-\mathrm{SR}_{\mathrm{t}} \text { for } \mathrm{SR}_{\mathrm{t}}>0
\end{gathered}
$$

where $t$ is time (day), NIWR is the net irrigation water requirement $(\mathrm{mm}), \mathrm{PWD}$ is the current ponding water depth $(\mathrm{mm})$, OPWD is the optimal ponding water depth $(\mathrm{mm})$, SR is surface runoff in the paddy field outlet ( $\mathrm{mm}), \mathrm{RF}$ is rainfall $(\mathrm{mm})$, and ER is effective rainfall.

\subsection{Calibration of Agricultural Reservoir Simulation through Optimizing RCFs}

The coefficients of lumped runoff models are usually optimized on the basis of measured data. The optimized coefficients not only characterize the model structure but also reflect the geographical features of the watershed, because the coefficients assume characteristic values according to the watershed [51]. Ishihara and Kobatake (1979) attempted to evaluate the coefficients of the Tank model [52]. For agricultural reservoirs located in ungauged catchments, it is difficult to directly calibrate the inflow against the catchment runoff owing to a lack of runoff measurement data. Furthermore, the calibration of outflow is also challenging owing to noise introduced in the sensor measurements from irrigation channels and because of insufficient measurement data. However, reservoir water volume data are accurately measured in, and available for, most agricultural reservoirs.

To overcome the difficulties regarding the individual calibration of inflow and outflow in this study, the RCFs optimized to the inflow and outflow were applied in the models to more accurately simulate reservoir water volume. This involves finding a correction ratio of the best inflow and outflow volume that would result in the minimum difference between the measured and simulated reservoir volumes. The RCFs applied in this study reflect the effect of inflow and outflow to simulate the best value of reservoir water volume and cannot be used to accurately calibrate individual inflow and outflow volumes. Nonetheless, an accurate simulation of reservoir water volume is essential for reservoir operation and management, and the RCF application method is expected to increase simulation accuracy.

To increase the applicability of RCFs, the optimum RCF values in different time periods were analyzed, instead of application of a single value. Inflow is largely affected by precipitation. Variations observed in monthly precipitation in Korea are high; $60 \%$ of the annual precipitation is concentrated from June to August, and this has a large influence on catchment runoff. Therefore, monthly RCFs were estimated in this study. Furthermore, the purpose of the reservoir outflow is to supply irrigation water, which is closely related to crop water requirement and precipitation. The outflow RCFs were also estimated every month, as crop growth varies in different time periods.

The best estimations of monthly inflow and outflow RCFs were achieved by setting the least square value of the difference between the measured and simulated reservoir volumes as the objective function. To increase the optimization efficiency, individual variables were set within certain ranges, and a range of $0-2.0$ was set for monthly reservoir inflow. This is because it was assumed that the volume from the catchment runoff which contributes to reservoir inflow is not likely to be more than twice the estimated daily runoff from the Tank model. Values below 1.0 were included in the range, because even a large inflow may contribute almost nothing to a change in reservoir water volume when the maximum volume capacity is approached, resulting in a negative value of inflow RCF. Thus, 
the inflow RCFs estimated in this study are the values which show the degree to which the inflow volume contributes to the reservoir water volume simulation, rather than the values used for the direct estimation of the actual water inflow.

In the case of outflow volume, the RCFs were applied to the simulated water volume required for irrigation, which is the maximum outflow volume ideal for irrigation and is different from the actual outflow volume. For example, the withdrawal of the maximum volume required for irrigation may not be problematic when the reservoir water volume is significant enough; however, when there is a shortage of stored water in the reservoir, lesser water must be withdrawn. In the agricultural reservoirs of Korea, a water depth threshold is applied to limit water withdrawal when the water depth is below the threshold. A 30-year average water depth is typically recommended as the threshold depth, but a specific depth is not enforced. The reservoir water volume at the threshold depth was applied when estimating the outflow RCFs in this study. Separate outflow RCFs were used in cases where the current reservoir water volume was lower or higher than the volume at the threshold depth.

In short, the RCFs applied for the optimized simulation of reservoir water volume were inflow $\mathrm{RCF}$, outflow RCFs when the volume was below or above the threshold depth, and the reservoir water volume at the threshold depth. An objective function was applied to estimate the RCFs that minimize the mean square errors of the differences between the measured and simulated reservoir water volumes. The equation is given in Equation (6):

$$
\begin{gathered}
\mathrm{S}_{\mathrm{t}}=f(t)=f(t-1)+F_{\text {inflow }}(t)-F_{\text {outflow }}(t) \\
F_{\text {outflow }}(t)=\mathrm{O}_{\mathrm{t}} \times \alpha_{\mathrm{i}}\left(1<\alpha_{\mathrm{i}}<2\right) \text { for } \mathrm{S}_{\mathrm{t}-1} \geq \mathrm{S}_{\text {limit }} \\
F_{\text {out flow }}(t)=\mathrm{O}_{\mathrm{t}} \times \beta_{\mathrm{i}}\left(0<\beta_{\mathrm{i}}<1\right) \text { for } \mathrm{S}_{\mathrm{t}-1}<\mathrm{S}_{\text {limit }} \\
F_{\text {inflow }}(t)=\mathrm{I}_{\mathrm{t}} \times \gamma_{\mathrm{i}}\left(0<\gamma_{\mathrm{i}}<2\right) \\
\text { OF }\left(\alpha_{\mathrm{i}}, \beta_{\mathrm{i}}, \gamma_{\mathrm{i}}, \mathrm{S}_{\text {threshold }}\right)=\min \sum\left\{\mathrm{Obs}_{\mathrm{t}}-S_{t}\right\}^{2}
\end{gathered}
$$

where $f(t)$ is the daily storage volume, $\mathrm{t}$ is time (day), $F_{\text {inflow }}(t)$ is the adjusted daily inflow by RCFs, and $F_{\text {outflow }}(t)$ is the adjusted daily outflow by RCFs. OF is the objective function for extracting the optimized RCFs, $\mathrm{Obs}_{t}$ is the measurement of daily storage volume, $\mathrm{S}_{t}$ is the simulation of daily storage volume, $I_{t}$ is the simulation of daily irrigation requirement, $\mathrm{O}_{t}$ is the simulation of daily inflow, and $S_{\text {limit }}$ is the threshold value of water storage for reducing outflow. $\alpha_{i}, \beta_{i}$, and $\gamma_{i}$ are the parameters for adjusting outflow and inflow. Each month has quite different runoff because of seasonality of rainfall; in addition, irrigation requirements are affected by monthly crop phenology. Therefore, in this study, $\alpha_{i}, \beta_{i}$, and $\gamma_{i}$ are applied as monthly parameters and thus we optimized 12 different values for each of parameters.

\subsection{Analysis of the Resilience of Reservoir Operations Using the Severity, Duration, and Intensity of Reservoir Recovery}

The resilience of agricultural reservoirs in this study is defined as recovery to the threshold storage level. In other words, the effect of climate change on reservoir operations was evaluated from the perspective of reservoir resilience via analysis of the speed at which reservoir water volume recovered, and this is similar to the analysis of recovery from natural disasters such as drought or floods. Therefore, we applied the water recovery concept to evaluate reservoir resilience to climate change, which the reservoir requires to recover to the stable level, as shown in Figure 2. First, we set the threshold water volume to identify the stable operation of the reservoirs. We applied a 10-year storage return period as the threshold value, which has been used widely for assessing the water supply capability of agricultural reservoirs in Korea [14]. Second, we estimated the water requirement for recovery, which indicates the gap between the threshold water volume and current storage. When the reservoir storage is significantly lower than the threshold volume, a large volume of water is required for the threshold to be reached, which is represented as the water required for recovery. In addition, if the reservoir storage is continuously below the threshold volume for a long time, its functioning as a water supplier could weaken. In other words, if it was deemed a reservoir drought 
and if this condition became severe and continued over a long term, we considered the resilience of the reservoir to worsen. Therefore, using Run theory, we considered the following as indicators of reservoir resilience and analyzed them: the duration, severity, and intensity of the water for recovery $[53,54]$. This theory is mostly used in drought characterization to analyze duration and intensity before recovery to a non-drought state [55,56]. Recently, the application of Run theory has been expanded with various drought analysis methodologies, such as the copula-based drought risk assessment and a nonlinear multivariate drought index [57,58]. In this study, the duration of water for recovery is expressed in days during which storage is continuously below the threshold value and the severity indicates a cumulative deficiency below the threshold water volume. Intensity is measured as the ratio of the severity to the duration, as shown in Figure 1.
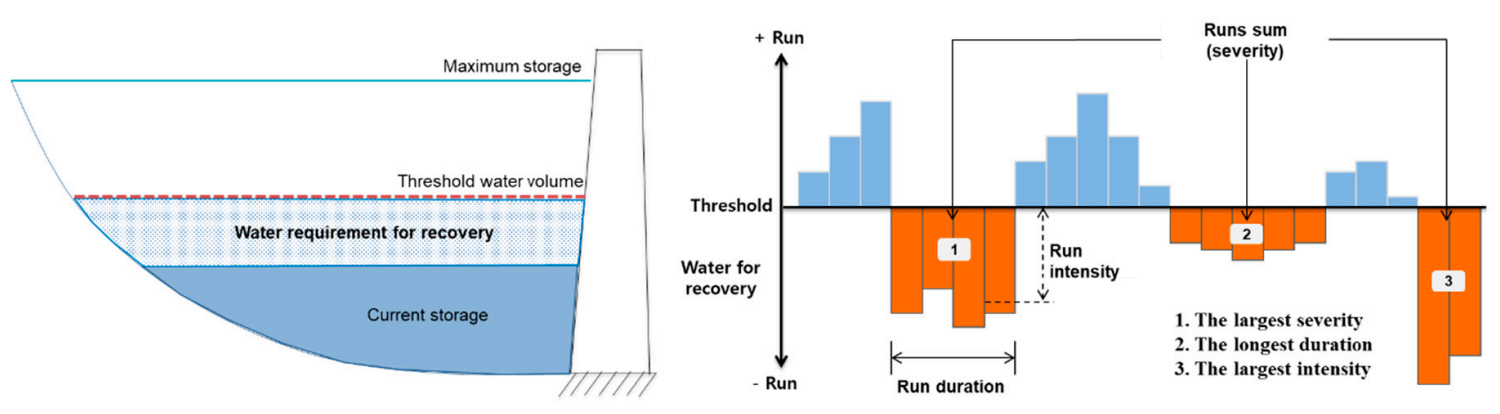

Figure 2. Application of concept of water requirement for recovery and Run theory for analyzing the resilience of a reservoir.

\subsection{Study Reservoirs and Climate Change Scenarios}

Reservoirs with various water storage capacities were investigated to reflect the diverse sizes and water storage capacities of reservoirs operated across Korea. The reservoirs selected for simulation in this study were agricultural reservoirs located in ungauged catchments (Figure 3) and the information of the selected reservoirs is shown in Table 1 . Kicheon reservoir has a water storage capacity of $2,164,000 \mathrm{~m}^{3}$, which is the typical capacity of an agricultural reservoir in Korea. A larger reservoir (Deokwoo reservoir) and a smaller reservoir one tenth the size of the Kicheon reservoir (Samchun reservoir) were also included in the simulations to investigate the calibration efficiency for reservoir water volume using RCFs over a wide range of reservoir sizes. Particularly for the Samchun reservoir, the water storage volume increased from $96,000 \mathrm{~m}^{3}$ to $210,000 \mathrm{~m}^{3}$ owing to a reservoir enlargement project, and the accuracy of calibration using RCFs was evaluated under changes in reservoir water volumes. The simulated reservoir water volume on the basis of the measured meteorological data available from 2008 to 2017 and the actual reservoir water volume measured over the same period were used to calibrate the simulated values for reservoir water volume. 

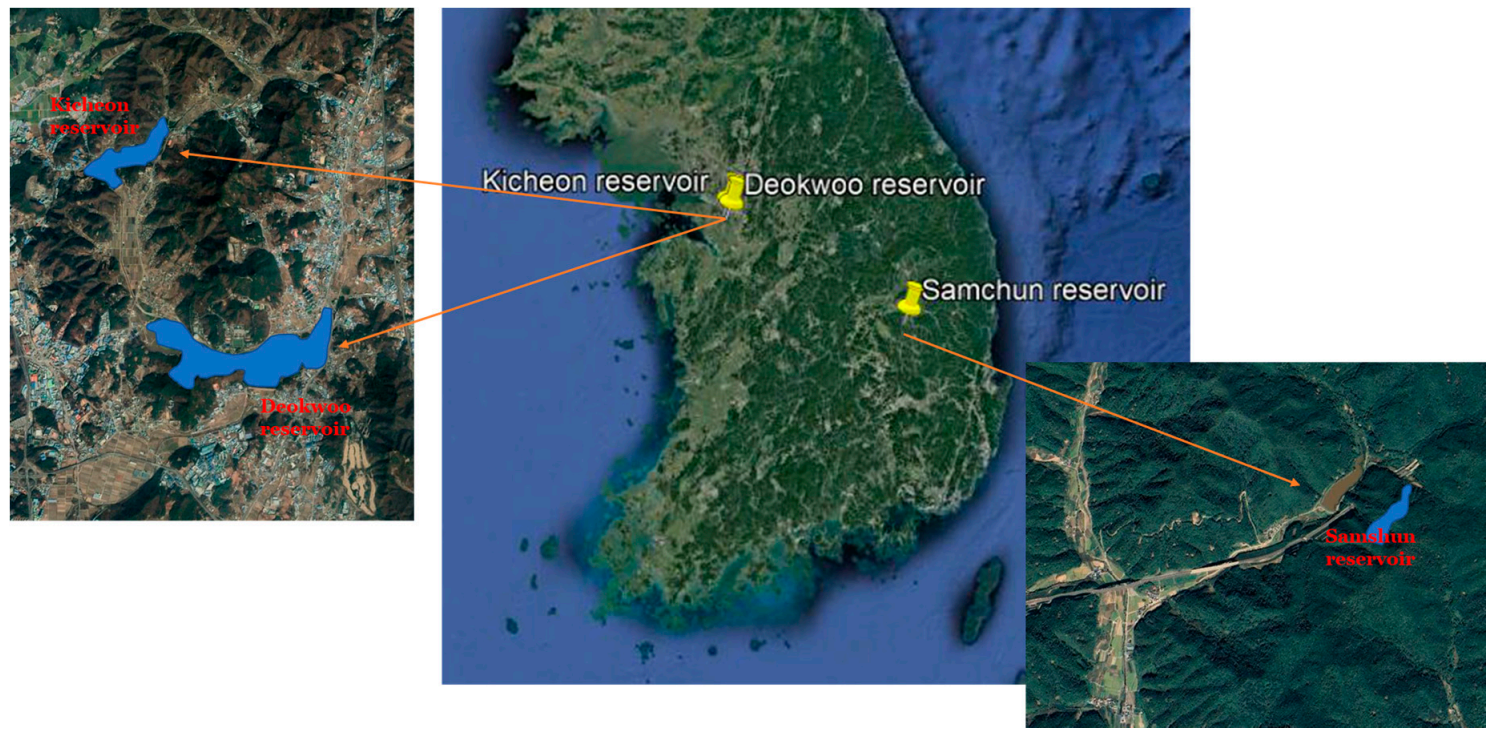

Figure 3. Study reservoirs.

Table 1. Variables of agricultural reservoirs (values per $1000 \mathrm{~m}^{3}$ ).

\begin{tabular}{ccccc}
\hline Reservoir & Kicheon & Deokwoo & $\begin{array}{c}\text { Sefore } \\
\text { Enlargement }\end{array}$ & $\begin{array}{c}\text { After } \\
\text { Enlargement }\end{array}$ \\
\hline $\begin{array}{c}\text { Maximum storage } \\
\text { Minimum storage }\end{array}$ & 2164 & 3547 & 96 & 219 \\
$\begin{array}{c}\text { Storage with 10-year return } \\
\text { period }\end{array}$ & 151 & 135 & 50 & 50 \\
\hline
\end{tabular}

To evaluate the effect of climate change, meteorological data from 2018 to 2099 were used to simulate reservoir water volumes. Past meteorological data were also obtained from the Suwon weather station, which covers the areas in which the investigated reservoirs are located. Future climate data were simulated using a general circulation model (GCM) considering representative concentration pathway $(\mathrm{RCP})$ scenarios, which have recently become available to the public. These provide the latest climate change scenarios adopted by the Intergovernmental Panel on Climate Change according to its fifth assessment report (AR5). There are four independent pathways: RCP 8.5 (high emissions, equivalent to SRES, A1F1, or A2), RCP 6.0 (intermediate emissions, B2), RCP 4.5 (intermediate emissions, $\mathrm{B} 1$ ), and RCP 2.6 (low emissions); the numbers represent the possible ranges of radiative forcing values $\left(\mathrm{W} / \mathrm{m}^{2}\right)$ for the year 2100 .

In this study, we used the climate change scenario with RCP 4.5 provided from the survey for actual conditions for impact and vulnerability assessment on climate change in agriculture and rural community entrusted to Korea Rural Community Corporation in Korea. This scenario was based on HadGEM2-RA (spatial resolution: $12.5 \mathrm{~km}$, temporal resolution: month/day/6-h/3-h), which are the global and regional climate models at the UK Met Office, Hadley Centre. In addition, Korea Meteorological Administration (KMA) provides climate projections based on HadGEM3-RA.

Climate data from the GCMs had to perform bias-correction for application to the specific area because these data are known to exhibit systematic biases. The climate variable (e.g., rainfall) in the grid box of a given size was provided. In this study, we applied Spatial Disaggregation Quantile Delta Mapping (SDQDM) to conduct bias correction of the climate data. SDQDM is the statistical post-processing method for spatial disaggregation and bias-correction, and it is designed to correct bias while preserving the long-term trend of all quantiles in climate projections. Thus, SDQDM has the advantage of maintaining an extreme long-term trend better than other methods [59,60]. Although 
there was a limitation in that only three reservoirs could be included in the simulations, we consider this study to be meaningful in terms of groundwork for future research intending to apply the RCF calibration method for reservoirs in ungauged catchments.

\section{Results and Discussion}

3.1. Analysis of the Applicability of RCF Calibration for the Simulation of Agricultural Reservoirs in Ungauged Catchments

The reservoir water volume measurements were compared with the simulated water volumes to analyze the efficiency of the RCF calibration method. Figures 4-6 show the measured reservoir water volume and the simulated water volume from before and after calibration using RCFs from 2008 to 2017. The simulated reservoir water volumes after calibration were closer to the measured water volumes than the uncalibrated values were.

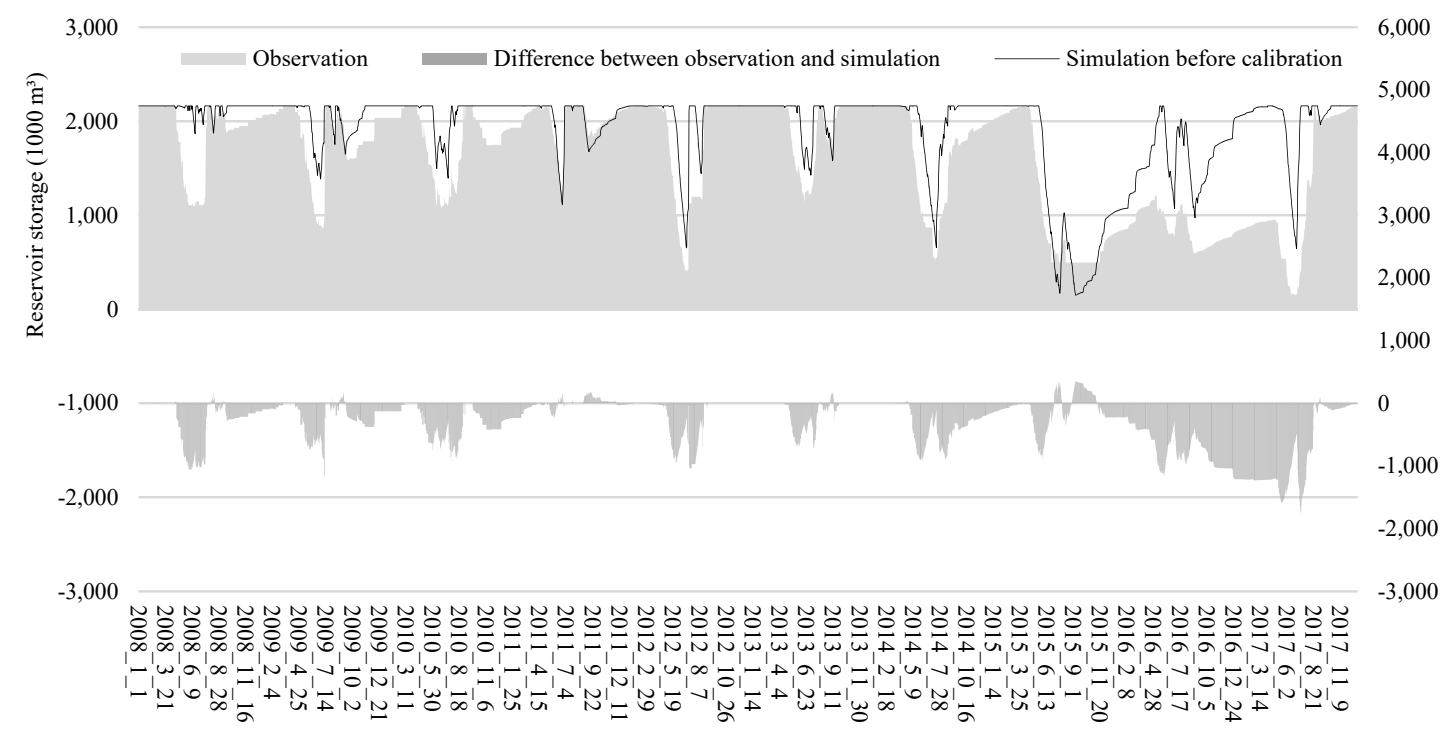

(a)

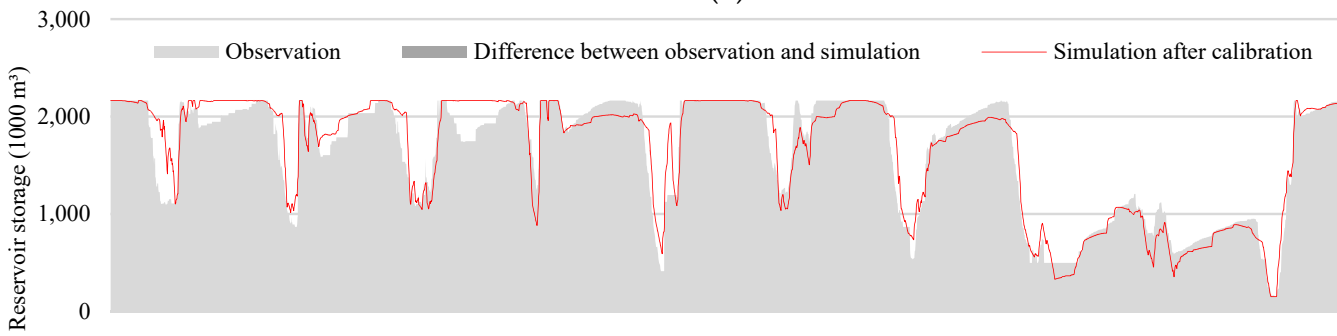

6,000 5,000

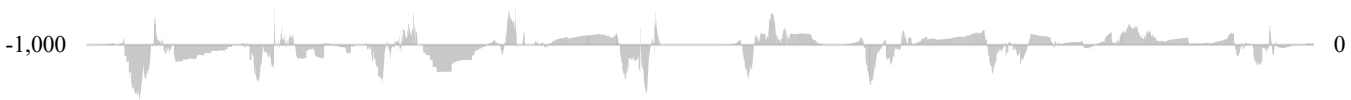

Figure 4. Simulation of water storage capacity of Kicheon reservoir before and after calibration using RCFs. (a) Before calibration (Kicheon reservoir); (b) after calibration (Kicheon reservoir). 


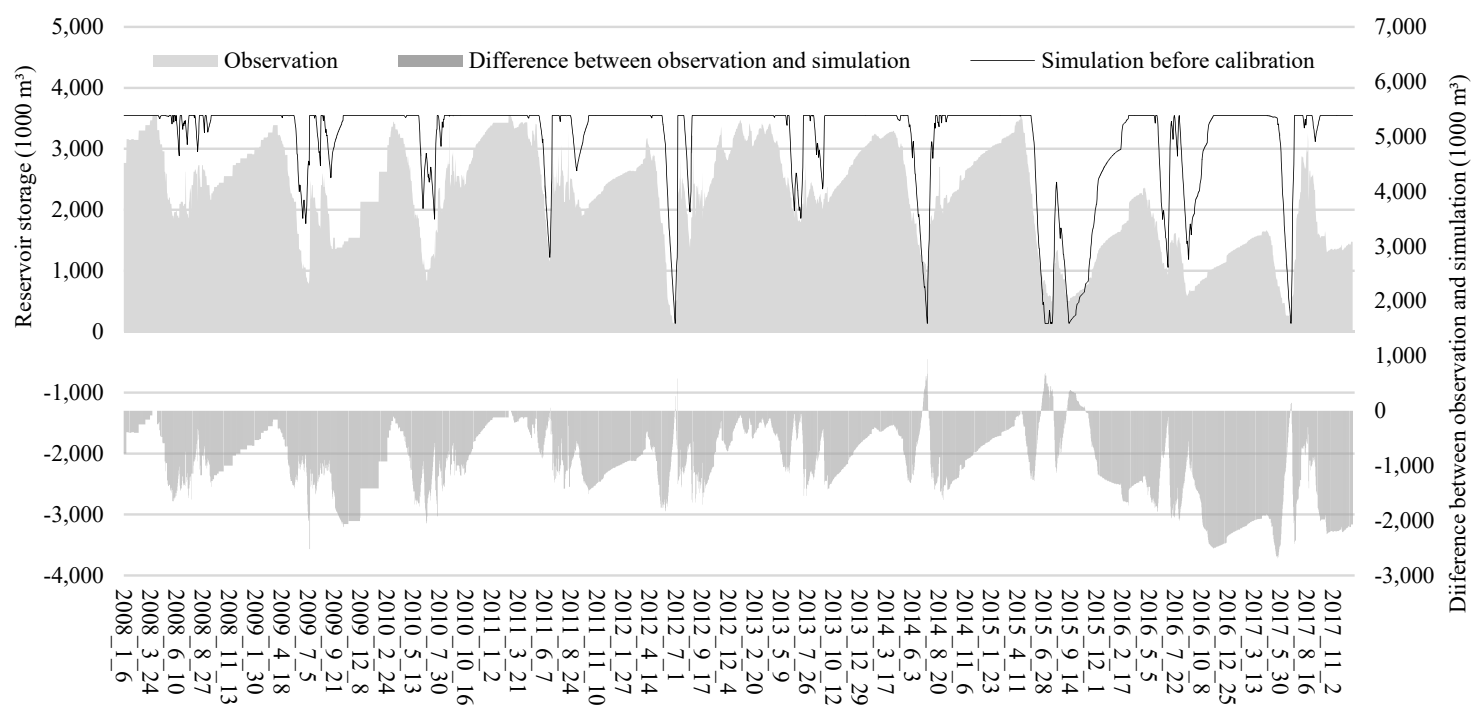

(a)

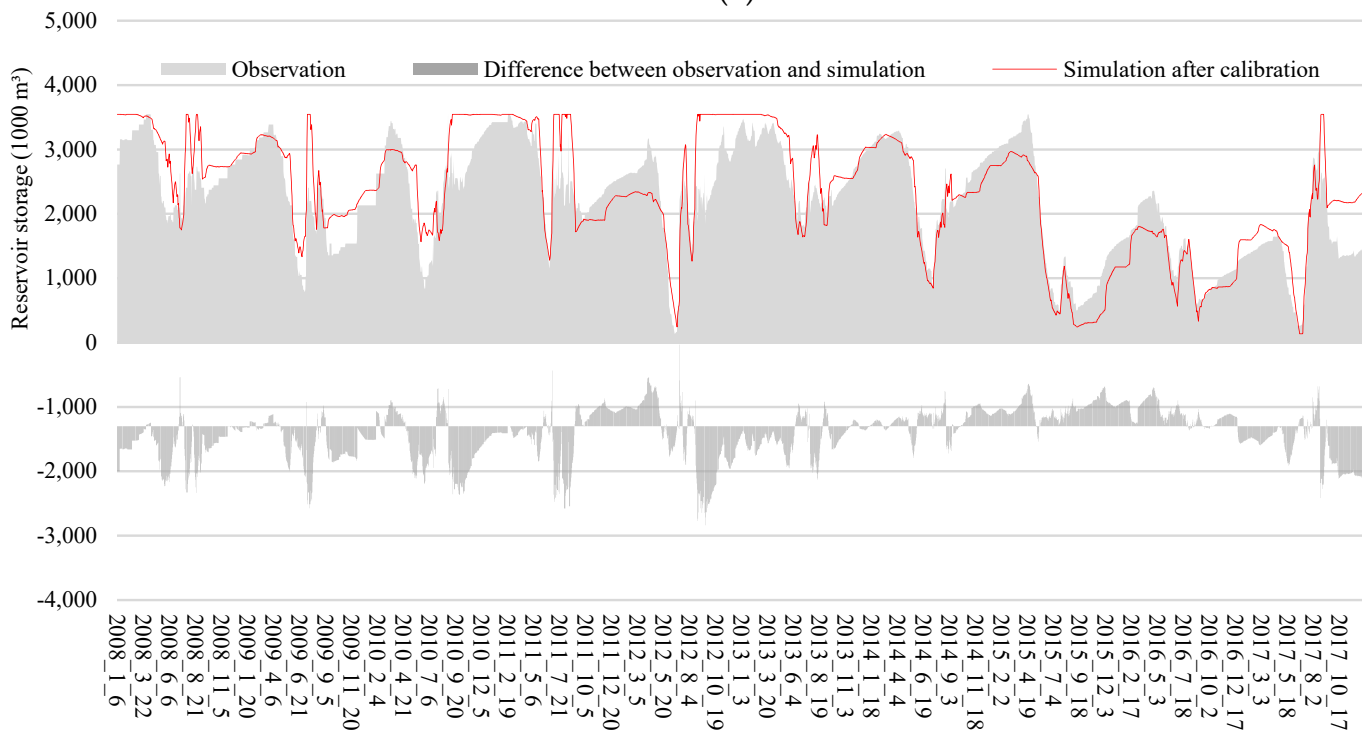

7,000

(b)

Figure 5. Simulation of water storage capacity of Deokwoo reservoir before and after calibration using RCFs. (a) Before calibration (Deokwoo reservoir); (b) after calibration (Deokwoo reservoir). 


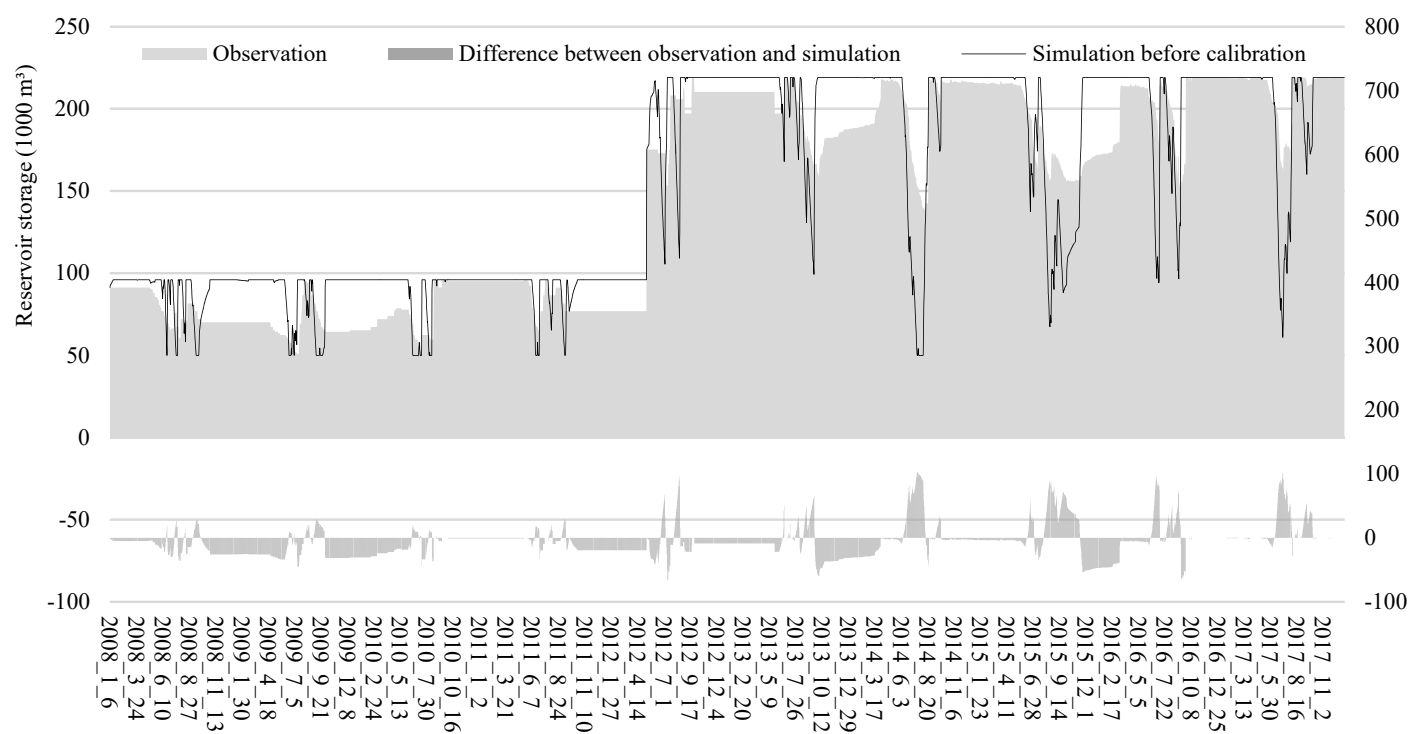

(a)

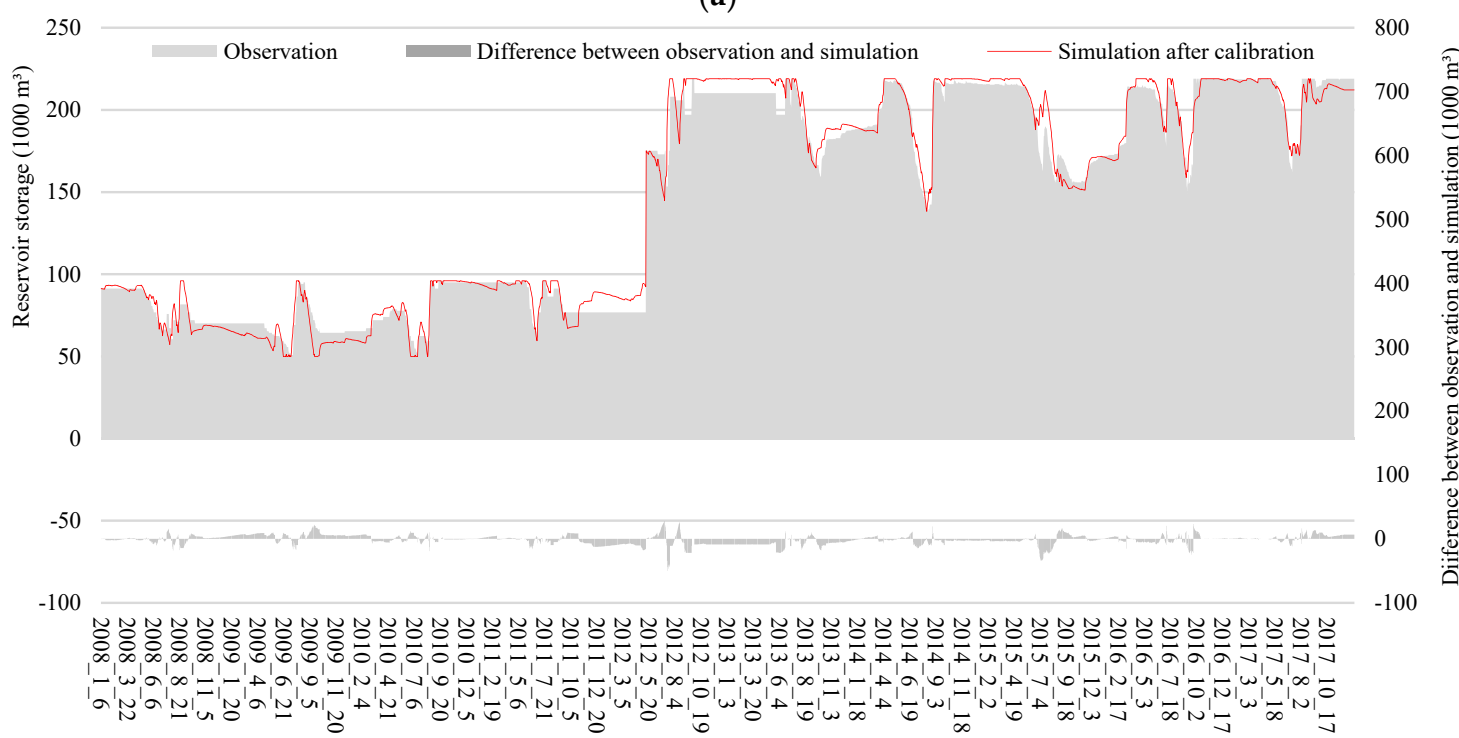

(b)

Figure 6. Simulation of water storage capacity of Samchun reservoir before and after calibration using RCFs. (a) Before calibration (Samchun reservoir); (b) after calibration (Samchun reservoir).

For the Kicheon reservoir, the simulated reservoir water volume without RCF calibration was higher than the measured water volume. This suggests that even when the actual water volume in the reservoir is insufficient, the simulation may indicate that there is enough water in the reservoir. Particularly in the period of 2015-2016, the measured reservoir water volume was primarily below $1000 \mathrm{~m}^{3}$, but simulations without calibration yielded reservoir water volumes of over $1000 \mathrm{~m}^{3}$ for these years. When the simulations were calibrated using RCFs, the simulated volumes differed from the measured volumes for certain time periods, but the simulation accuracy increased when compared to the accuracy of the uncalibrated simulations (Figure 7). Without calibration, the correlation between the simulated and measured reservoir water volumes was very low; however, the correlation increased after calibration of the simulated water volumes, and a linear relationship between simulated and measured volumes was observed with a correlation coefficient (R2) value of 0.9 , indicating that the simulated reservoir values after calibration closely matched the measured values. Calibration 
using RCF was further conducted in simulations of water volumes in reservoirs of different sizes to test the applicability of the method.

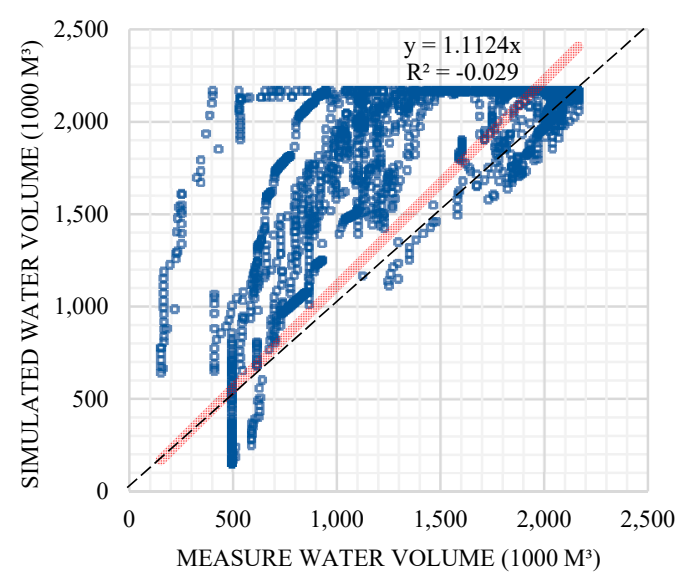

(a)

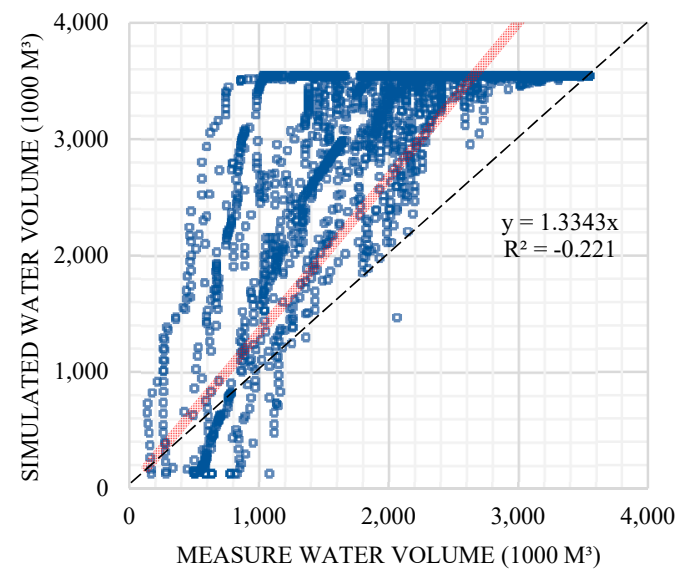

(c)

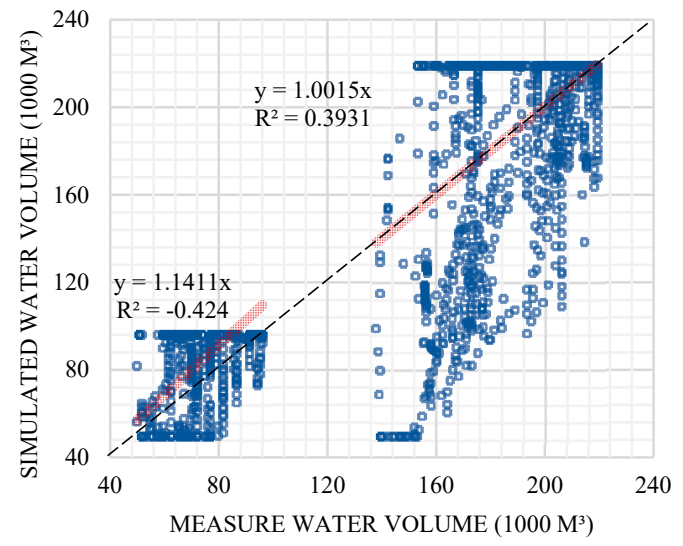

(e)

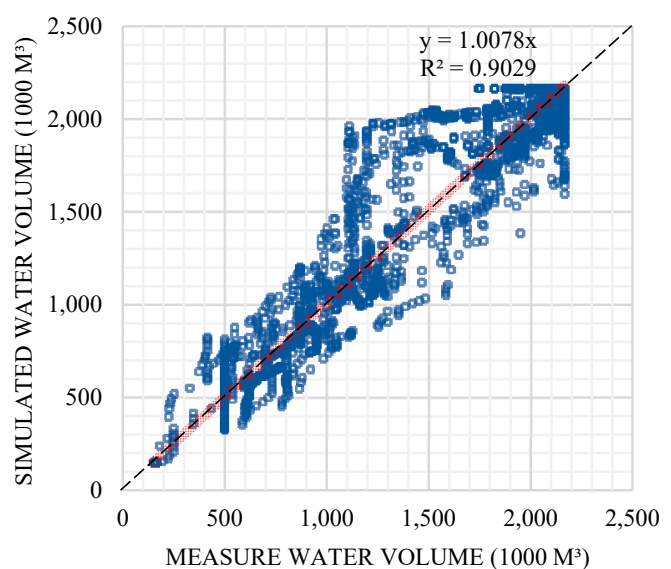

(b)

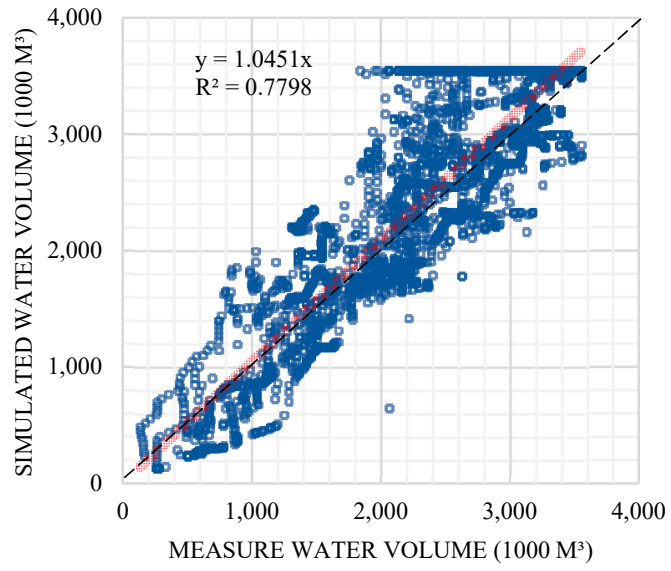

(d)

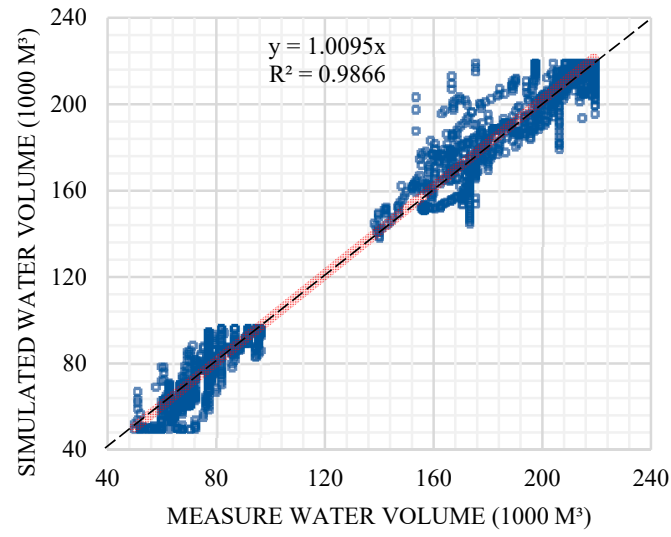

(f)

Figure 7. Comparison of measured and simulated reservoir water volume in the Kicheon, Deokwoo, and Samchun reservoirs to evaluate the accuracy of RCF calibration. (a) Before calibration (Kicheon reservoir); (b) after calibration (Kicheon reservoir); (c) before calibration (Deokwoo reservoir); (d) after calibration (Deokwoo reservoir); (e) before calibration (Samchun reservoir); (f) after calibration (Samchun reservoir). 
In the Deokwoo reservoir, which is larger than the Kicheon reservoir, the variations in measured water volumes were higher; consequently, the accuracy of the simulated water volumes after calibration was lower than that of the Kicheon reservoir. However, the calibration still resulted in an increased correlation between the simulated and measured water volumes, as shown in Figure 7. For example, in the graph that plots the simulated and measured water volumes with a 1:1 reference line, most of the simulated values were higher than the measured values, and the correlation between the two increased after calibration. The measured water volume decreased during the years 2016-2017 in the Deokwoo reservoir, as in the Kicheon reservoir, but the simulation without calibration did not reflect a decrease in water volume. When the simulated values were calibrated using RCFs, the simulation accuracy increased, especially under high temporal variability of reservoir water volume.

The RCF calibration method was further applied to the simulations of water volume in the Samchun reservoir, which is much smaller than the Deokwoo or Kicheon reservoirs. The Samchun reservoir was enlarged in 2012, when the maximum water storage increased from 96 to $219 \mathrm{~m}^{3}$. Thus, RCF calibration was applied to water volume simulations before and after the increase in reservoir capacity. When compared to the measured water volumes, the simulated values without calibration yielded higher water volumes prior to reservoir enlargement, but the simulated volumes were significantly lower than the measured volumes after the reservoir was enlarged. It can be seen from Figure 7 that RCF calibration of simulated water volumes increased the simulation efficiency in the case of the small reservoir that underwent a change in water storage capacity. The correlation coefficients of the linear relationship between simulated and measured water volumes were significantly high, suggesting that calibration using RCFs yields better simulated values for small-scale reservoirs when compared to those of larger reservoirs.

Differences in the simulated and measured reservoir water volumes may be due to an overestimation of inflow or an underestimation of outflow, but the source of such differences cannot be determined with certainty owing to a lack of inflow and outflow measurements in reservoirs within ungauged catchments. Yet, an accurate simulation of reservoir water volume is critical for the operation of reservoirs in response to future climate change. The calibration method using RCFs, based on the relationship between inflow and outflow, has been shown to increase the accuracy of water volume simulations in reservoirs of various sizes, demonstrating its potential as an important pre-analysis tool to assess the effect of climate change on agricultural reservoir management. Differences in simulated and measured water volumes impede the efficient operation of reservoirs and may result in an underestimation of the negative effects of climate change. An overestimation of reservoir water volume during evaluations of reservoirs for drought tolerance under future climate change scenarios may particularly pose problems with regard to establishing reservoir operation standards in response to climate change.

\subsection{Assessment of Climate Change Impact on Resilience of Agricultural Reservoirs Using Run Theory}

\subsubsection{Simulation of Reservoir Storage under a Climate Change Scenario from 2018 to 2099}

Figure 8 showed that variations in water volume of the Kicheon and Deokwoo reservoirs were higher in the RCF-calibrated simulations when compared to those in the uncalibrated simulations, especially for the Deokwoo reservoir, of which the climate-change-derived variations in water volume with RCF calibration were significantly higher. Such results indicate that uncalibrated reservoir water volume simulations may underestimate the impact of climate change by predicting that drastic decreases in reservoir water volume will occur less frequently. However, the simulated reservoir water volume after RCF calibration showed a wider variation range under climate change, which highlights the importance of the RCF calibration method for better prediction of, and response to, climate change. The sensitivity of reservoir water volume to climate change in the medium-sized Deokwoo reservoir suggests that the importance of RCF calibration may be higher for the Deokwoo reservoir than for the Kicheon reservoir. In the case of the small-sized Samchun reservoir, the uncalibrated 
simulation results showed a shortage in reservoir water volume under climate change. However, when the simulation results for the Samchun reservoir were calibrated using RCFs, the analysis of future changes in water volume showed only two incidents in which the water volume decreased below $100,000 \mathrm{~m}^{3}$ (Figure 8). While appropriate responses to climate change are important, an overestimation of climate change impact may also disrupt the operation of reservoirs, as the overestimated impact may lead to a false indication of water shortage for irrigation. Therefore, RCF calibration can contribute to the reduction of underestimation as well as overestimations of climate change impact.

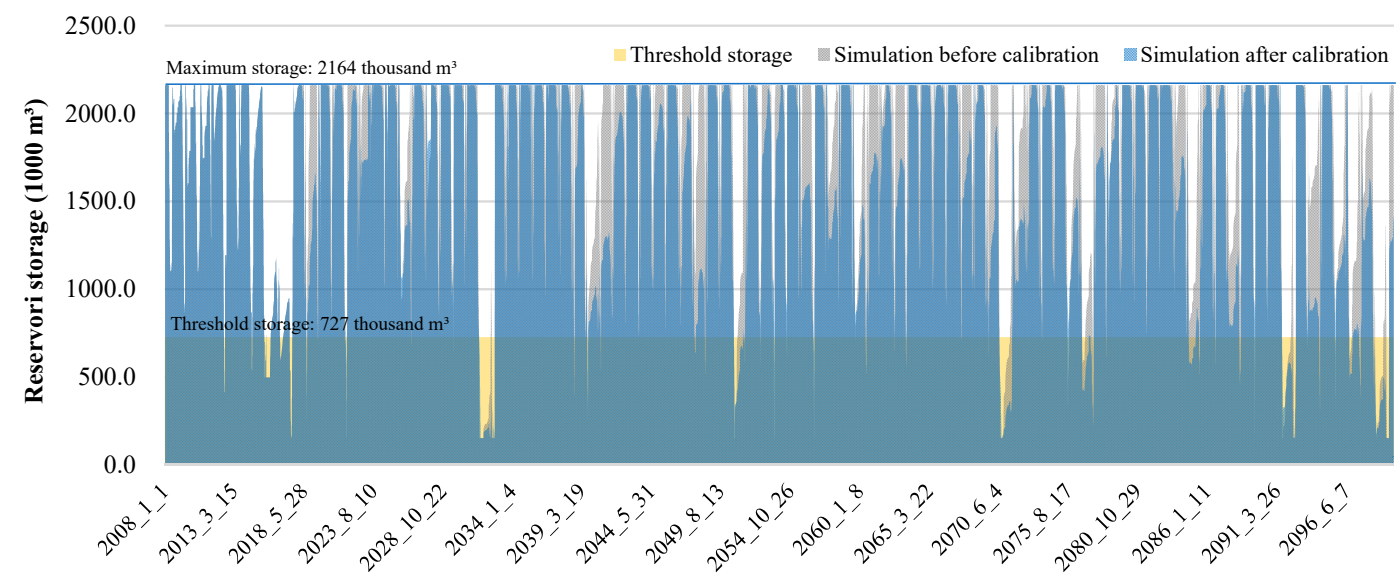

(a)

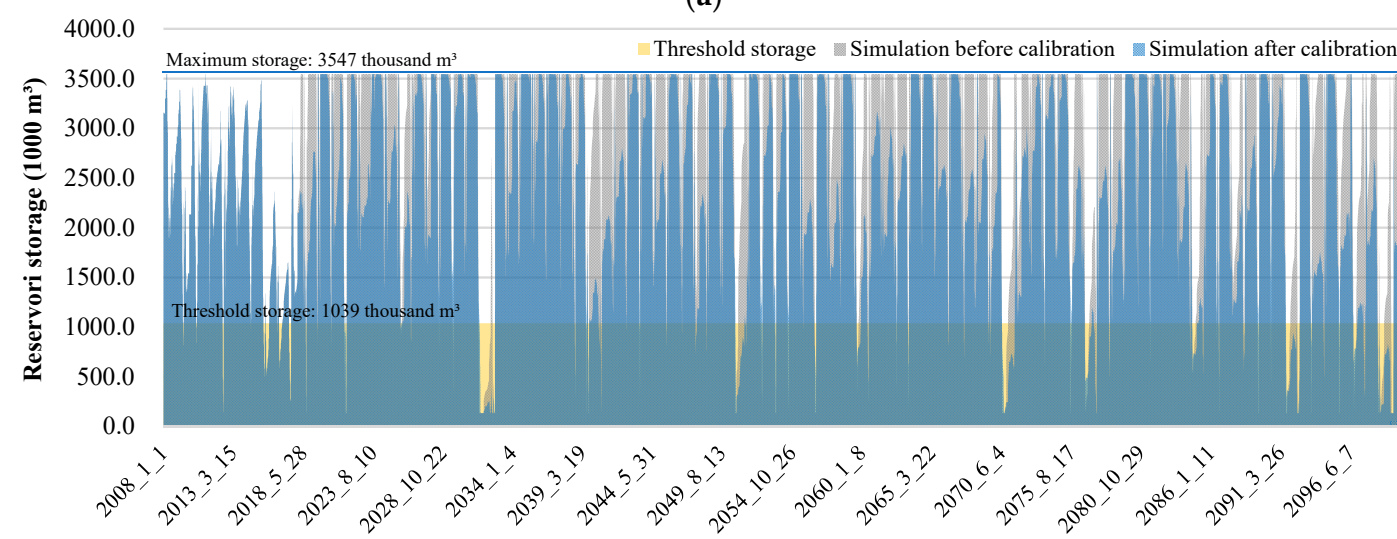

(b)

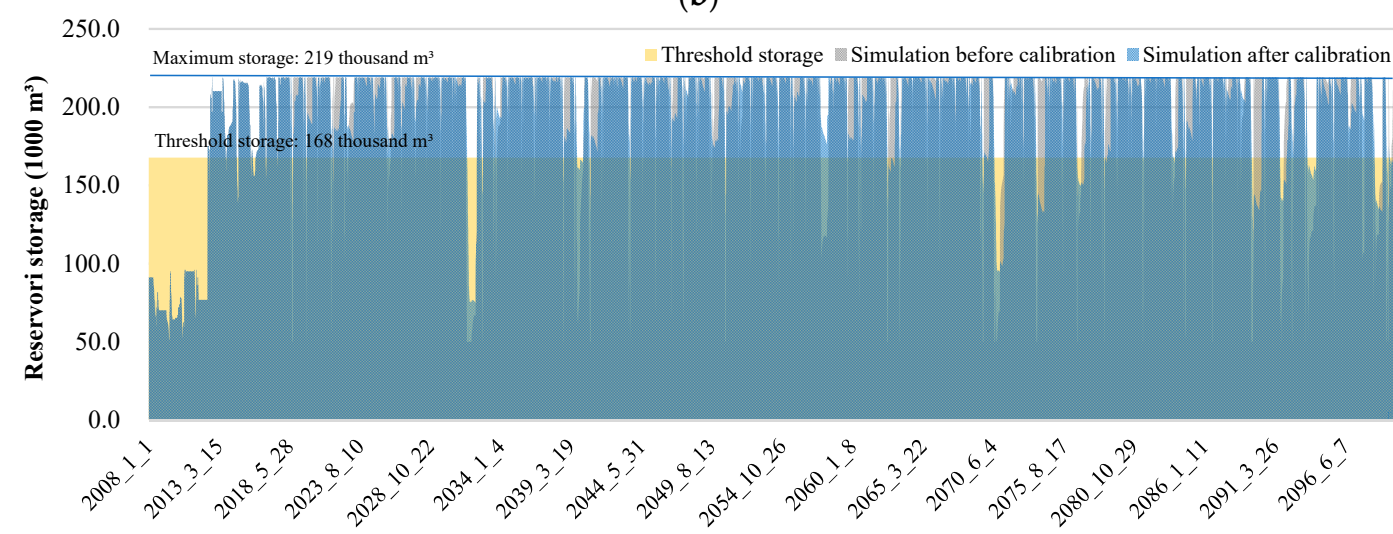

(c)

Figure 8. Simulation of reservoir water storage in Kicheon, Deokwoo, and Samchun reservoirs from 2008 to 2099 before and after calibration. (a) Kicheon reservoir; (b) Deokwoo reservoir; (c) Samchun reservoir. 
The quantitative analysis of changes in the climate change impact of reservoir water volume simulations before and after RCF calibration was achieved via analysis of the frequency at which reservoir water volume decreases below its threshold level (set as the water volume during a drought with a 10-year return period from 2008 to 2017). The histogram in Figure 9 shows the frequency at which the water volume decreased below the threshold level. The $X$-axis indicates the interval of storage, and the $Y$-axis indicates the number of days when the daily water volume is below the threshold level during 2008-2017.

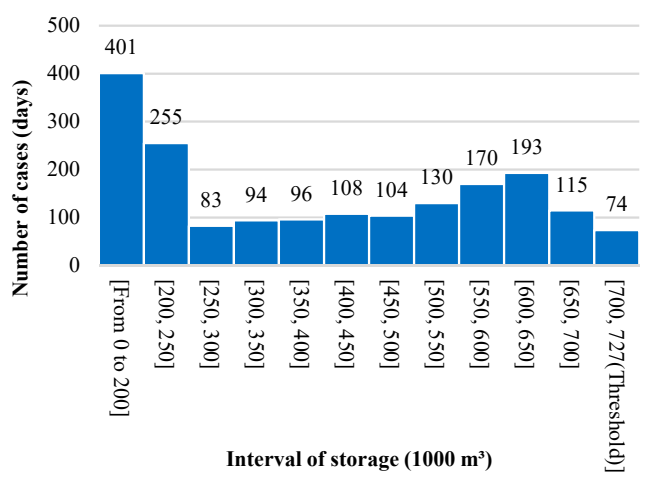

(a)

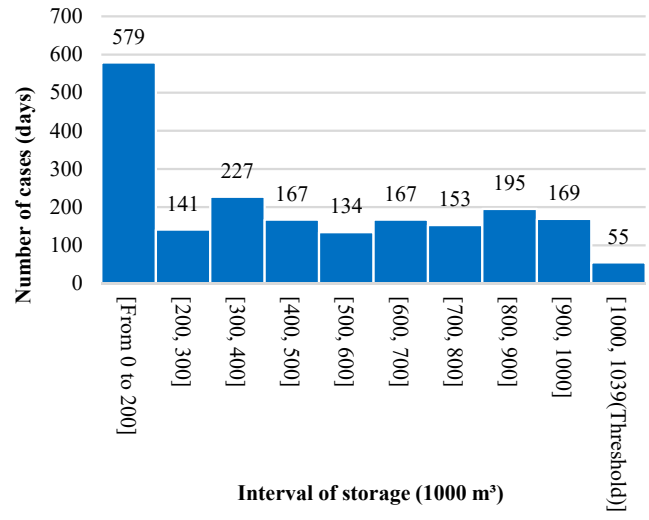

(c)

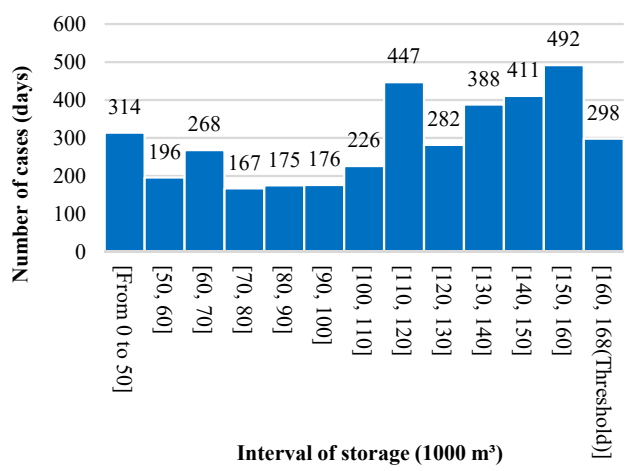

(e)

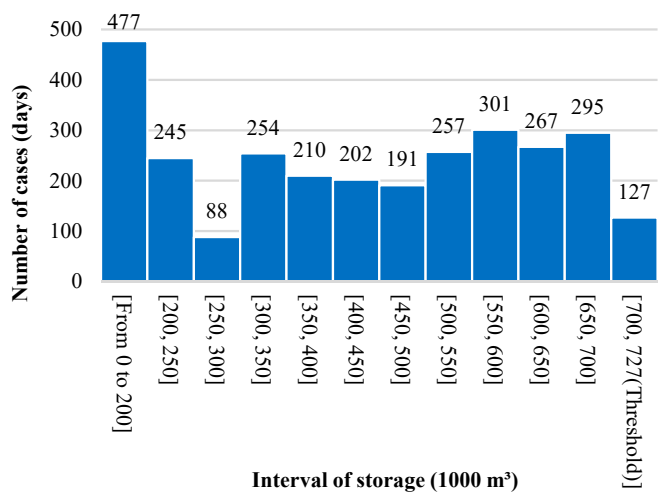

(b)

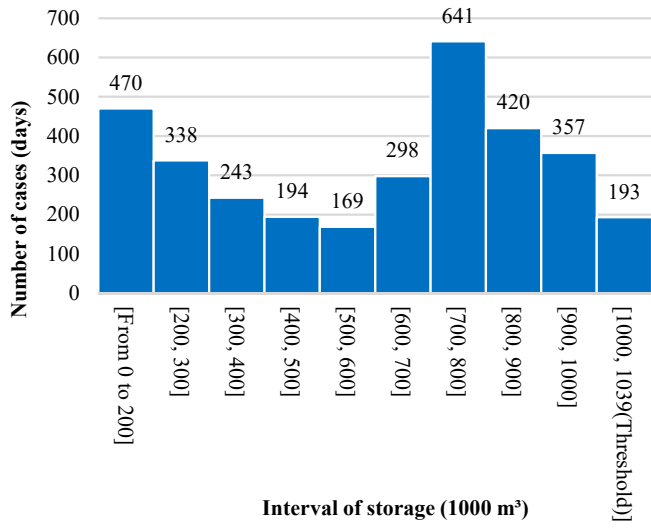

(d)

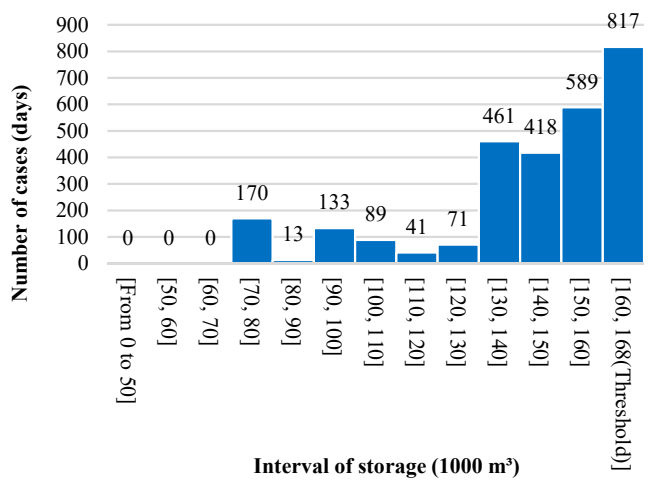

(f)

Figure 9. Histograms of simulated reservoir water storages below threshold level in Kicheon, Deokwoo, and Samchun reservoirs from 2008 to 2099 before and after calibration. (a) Before calibration (Kicheon reservoir); (b) after calibration (Kicheon reservoir); (c) before calibration (Deokwoo reservoir); (d) after calibration (Deokwoo reservoir); (e) before calibration (Samchun reservoir); (f) after calibration (Samchun reservoir). 
For the Kicheon reservoir, the average daily water volume in the 10-year drought period was $727,000 \mathrm{~m}^{3}$. Without calibration, the simulation results show that the water volume will decrease below the threshold 2914 times in the future. Out of such occurrences, the frequency at which the water volume will decrease between the dead storage value less than 200,000 $\mathrm{m}^{3}$ will be 401, and that between $200,000 \mathrm{~m}^{3}$ and $250,000 \mathrm{~m}^{3}$ will be 255 . However, the simulation results obtained for RCF calibration show a frequency of 2914, which is higher than that without calibration by more than 1000 counts. The frequency at which the water volume was predicted to decrease below $200,000 \mathrm{~m}^{3}$ was 477 times, which is the most frequent estimation. The most significant difference between the calibrated and uncalibrated simulation results was between $500,000 \mathrm{~m}^{3}$ and $727,000 \mathrm{~m}^{3}$, which is the threshold volume. The frequency of occurrence was 682 without calibration but 1247 with calibration.

For the Deokwoo reservoir, decreases in water volume below the threshold value of 1,039,000 $\mathrm{m}^{3}$ occurred 1987 times. The frequency of occurrence, however, increased to 3323 times with RCF calibration. The frequency of occurrence between the dead storage volume less than $200,000 \mathrm{~m}^{3}$ was the highest. With calibration, the results show a significant increase in the occurrence of decreases in water volume between $700,000 \mathrm{~m}^{3}$ and 1,039,000 $\mathrm{m}^{3}$, which is the threshold volume. For example, the frequency of occurrence in the range of $700,000 \mathrm{~m}^{3}$ to $1,039,000 \mathrm{~m}^{3}$ increased from 572 , in the uncalibrated simulations, to 1611 in the calibrated simulations, which is approximately a 2.8-fold increase in frequency. Thus, the calibration of reservoir water volume simulation significantly improves the prediction of the occurrence of decreases in water volume below the threshold volume, thereby affecting the response strategy to climate change in terms of reservoir operations, especially in the management of reservoir water volume during drought periods.

In the case of the Samchun reservoir, the water volume during the 10-year drought was $168,000 \mathrm{~m}^{3}$, and the frequency of occurrence of the simulated water volume below the threshold was 3840 without calibration and 2802 with calibration. This indicates that in contrast to the Kicheon and Deokwoo reservoirs, climate change impact may be overestimated without calibration for the Samchun reservoir. An underestimation of climate change impact can disrupt the operation of reservoirs in response to climate change, but an overestimation can decrease the efficiency of reservoir operation.

\subsubsection{Assessment of Climate Change Impacts on the Duration and Intensity of Reservoir Drought}

The analysis of the frequency of occurrence only shows the number of times that the reservoir water volume is within certain ranges and therefore presents limitations with respect to the analysis of drought intensity. Therefore, a threshold reservoir water volume was established, and decreases in water volume below the threshold volume were designated as the reservoir drought level. The water volume required for recovery from reservoir drought was calculated to analyze the duration and intensity of a drought under climate change. The threshold volume was set as the volume during a 10-year drought, as in the analysis of frequency of occurrence.

For the Kicheon reservoir, the number of consecutive days in which the water volume was predicted to be below the threshold in the studied future period is 322 days without calibration, and 434 days with calibration. Thus, the calibrated simulation resulted in a significantly longer period of predicted reservoir drought (Figure 10). The drought intensity (represented by the water volume required for recovery during the period of reservoir drought) was $486,000 \mathrm{~m}^{3}$ for 75 days without calibration. When calibration was conducted, a maximum intensity of $506,000 \mathrm{~m}^{3}$ was required for 426 consecutive days. After calibration with RCF, the duration of continued reservoir drought intensity can be more than 350 days with a required volume of over $300,000 \mathrm{~m}^{3}$. This suggests that reservoir water volume may be maintained at a low level for a long period of time. This may interfere with the stable operation of reservoirs and thereby decrease the reservoir's resilience to climate change. 


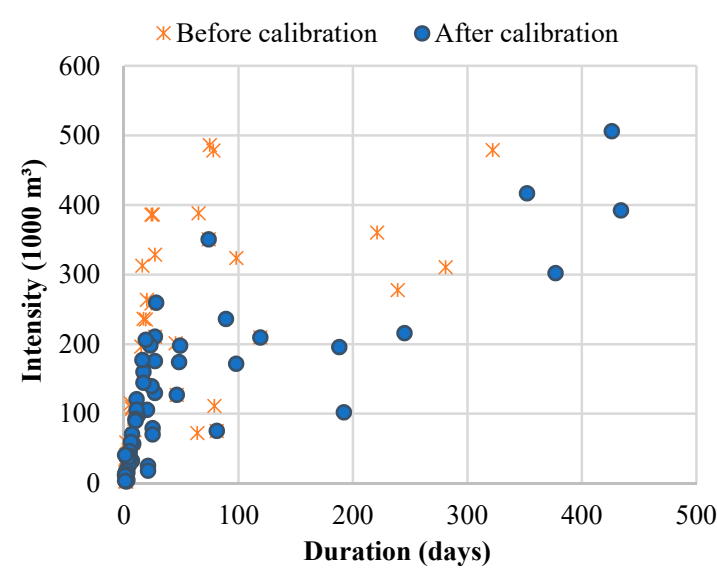

(a)

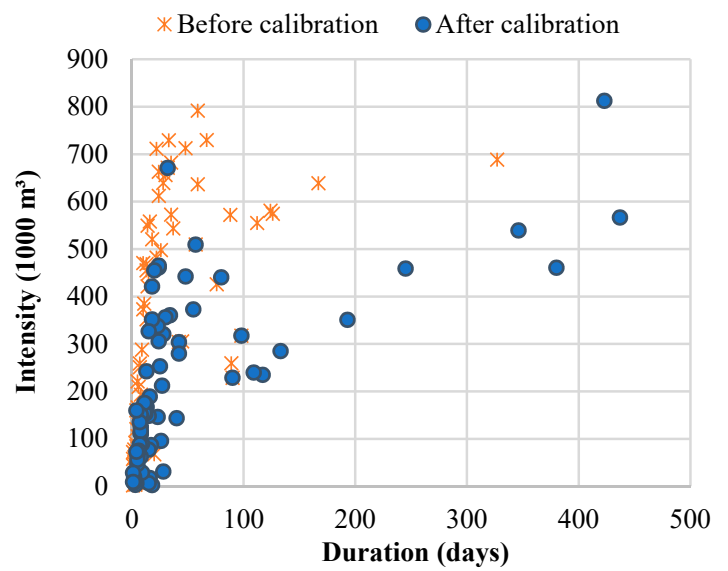

(b)

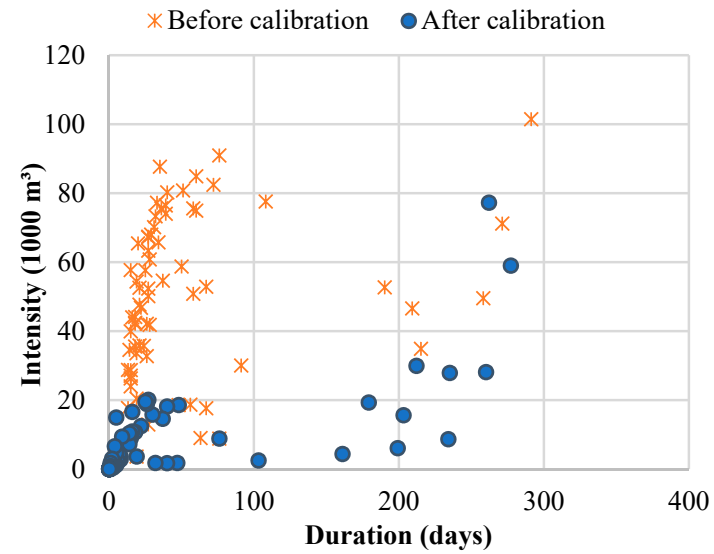

(c)

Figure 10. Intensity and duration of reservoir drought conditions of Kicheon, Deokwoo, and Samchun agricultural reservoirs. (a) Kicheon reservoir; (b) Deokwoo reservoir; (c) Samchun reservoir.

Similar results were found for the Deokwoo reservoir. The maximum intensity of reservoir drought increased from a required water volume of $792,000 \mathrm{~m}^{3}$ in the uncalibrated simulation to $813,000 \mathrm{~m}^{3}$ in the calibrated simulation, and the maximum drought duration increased from 327 to 437 days, respectively. Figure 10 also shows an increase in the consecutive occurrence of reservoir droughts that are predicted to continue for a long period of time.

In contrast to the maximum reservoir drought period of the Kicheon and Deokwoo reservoirs, that of the Samchun reservoir decreased from 291 to 277 days in uncalibrated and calibrated simulations, 
respectively, and the maximum intensity also decreased from 101,000 $\mathrm{m}^{3}$ to $77,000 \mathrm{~m}^{3}$, respectively. A vulnerability assessment using the duration and intensity of drought also showed a decrease in intensity values after RCF calibration, especially when the duration exceeded 150 days (Figure 10). This result suggests that climate change may have a relatively small impact on small-sized reservoirs, and that if water volume simulation results without calibration are referenced for strategic operations of small reservoirs in response to future climate change, irrigation water supply efficiency may be reduced. Using simulation results without RCF calibration may lead to restrictions imposed on irrigation water supply, even when there is enough water available for stable reservoir operation.

We have shown that using RCF calibration for the water volume simulations of reservoirs located in ungauged catchment areas can significantly influence reservoir operations in response to future climate change conditions. As the impact of climate change may be under- or overestimated depending on reservoir characteristics such as size, detailed calibrations are needed for reservoirs in ungauged catchment areas.

\section{Conclusions}

Agricultural reservoirs are important water resource management facilities that connect water resources and food security, but they are small in size and serve only one purpose: irrigation water supply. Therefore, studies on agricultural reservoirs are lacking in comparison to those on other water resource management facilities, such as large-scale multipurpose dams. In this study, we assessed the impact of climate change and the role of the calibration method for reservoir water volume simulations through the optimization of RCFs and provided an analysis of drought resilience in agricultural reservoirs.

The importance of a stable water supply for agricultural irrigation is increasingly emphasized for future food security. Accurate simulations of reservoir water volume are especially critical for rice-growing regions where water is supplied from reservoirs. However, measurement data are lacking for small agricultural reservoirs in ungauged catchment areas, which poses limitations to the calibration of water inflow. Therefore, instead of the development of a new model on water inflow and outflow, calibration of reservoir water volumes in ungauged catchment areas was conducted via application of RCFs to inflow simulation results using the Tank model, which is typically used in agricultural reservoir model simulations in Korea.

The RCFs were applied to the simulations of reservoir outflow, which correspond to irrigation water supply, and a calibration method for the accurate simulation of reservoir water volume was developed through the optimization of simulated water volume to measured water volume. In particular, the RCFs calibration could be applicable in a reservoir drought condition. For example, the simulation of storage was much different from observation especially in the drought periods from 2015 to 2017 in the Kicheon reservoir, and the RCF calibration reduced the difference between simulation and observation. In addition, the agricultural reservoir showed a significant fluctuation and this study showed that RCF calibration could reflect the fluctuation of storage.

In this study, we also focused on the importance of the calibration method especially in climate change and thus assessments of the impact of future climate change on reservoir operations were conducted by comparing the simulated water volumes before and after RCF calibrations. Furthermore, we applied the concept of "water requirement for recovery" to analyze reservoir drought conditions, and the duration and intensity of reservoir droughts at different volume levels were analyzed to assess reservoir resilience under climate change.

The results showed that RCF calibration can contribute to more accurate assessment of climate change impacts. In particular, the simulation calibrated by RCF showed a significantly longer period of predicted reservoir drought in Kicheon reservoir, and it means that using simulation results without RCF calibration could underestimate climate change impacts on reservoir drought conditions. In the case of the Samchun reservoir, which is very small in size, the intensity and duration of reservoir droughts were decreased in the calibrated simulation in comparison to the simulation before RCFs calibration. 
Since calibration was only applied to the simulations of three reservoirs, further study is required for a more general application of the method. More case studies are also required for investigating the potential use of the data on reservoir drought levels and the water volume required for the recovery required for reliable reservoir operations. Nonetheless, this study may serve as groundwork for increasing the accuracy and efficiency of water volume simulations for agricultural reservoirs in ungauged catchment areas and for reducing uncertainty in reservoir management under climate change. Although this study was conducted on reservoirs in Korea, we expect that our results will contribute to future reservoir management in other Asian countries, such as Japan and Thailand, where agricultural reservoirs supply water to large rice-growing districts.

Author Contributions: Conceptualization, S.-H.L., S.-H.Y., and J.-Y.C.; methodology, S.-H.L., and S.S.; validation, S.-H.L., S.-H.Y., and J.P.; formal analysis, S.-H.L., S.S., and S.-H.Y.; writing-Original draft preparation, S.-H.L.; visualization, S.-H.L. and S.-H.Y. All authors have read and agreed to the published version of the manuscript.

Funding: This research was funded by (Chonnam National University) grant number (2015-2865) The measured data of agricultural reservoir was provided from Korea Rural Community Corporation.

Conflicts of Interest: The authors declare no conflict of interest.

\section{References}

1. Ehsani, N.; Vörösmarty, C.I.; Fekete, B.M.; Stakhiv, E.Z. Reservoir operations under climate change: Storage capacity options to mitigate risk. J. Hydrol. 2017, 555, 435-446. [CrossRef]

2. Jain, S.K.; Bhunya, P. Reliability, resilience and vulnerability of a multipurpose storage reservoir/Confiance, résilience et vulnérabilité d'un barrage multi-objectifs. Hydrol. Sci. J. 2008, 53, 434-447. [CrossRef]

3. Brenkert, A.L.; Malone, E.L. Modeling Vulnerability and Resilience to Climate Change: A Case Study of India and Indian States. Clim. Chang. 2005, 72, 57-102. [CrossRef]

4. Fallah-Mehdipour, E.; Haddad, O.B.; Loáiciga, H.A. Climate-environment-water: Integrated and non-integrated approaches to reservoir operation. Environ. Monit. Assess. 2019, 192, 60. [CrossRef] [PubMed]

5. Shiau, J.-T.; Hung, Y.-N.; Sie, H.-E. Effects of Hedging Factors and Fuzziness on Shortage Characteristics During Droughts. Water Resour. Manag. 2018, 32, 1913-1929. [CrossRef]

6. Qiu, J.; Shen, Z.; Hou, X.; Xie, H.; Leng, G. Evaluating the performance of conservation practices under climate change scenarios in the Miyun Reservoir Watershed, China. Ecol. Eng. 2020, 143, 105700. [CrossRef]

7. Vano, J.A.; Scott, M.J.; Voisin, N.; Stöckle, C.O.; Hamlet, A.F.; Mickelson, K.E.B.; Elsner, M.M.; Lettenmaier, D.P. Climate change impacts on water management and irrigated agriculture in the Yakima River Basin, Washington, USA. Clim. Chang. 2010, 102, 287-317. [CrossRef]

8. Lauri, H.; De Moel, H.; Ward, P.J.; Räsänen, T.A.; Keskinen, M.; Kummu, M. Future changes in Mekong River hydrology: Impact of climate change and reservoir operation on discharge. Hydrol. Earth Syst. Sci. Discuss. 2012, 9, 6569-6614. [CrossRef]

9. Mhagama, M.L. Vulnerability and resilience of dry land irrigation farming schemes against climate change: A case of Ruvuma Basin. South East. Tanzan. 2020. [CrossRef]

10. Bomhof, J.; Tolson, B.A.; Kouwen, N. Comparing single and multi-objective hydrologic model calibration considering reservoir inflow and stream flow observations. CWRA/ACRH 2019, 44, 319-336.

11. Sleziak, P.; Danko, M.; Holko, L. Testing of an alternative approach to calibration of a hydrological model under varying climatic conditions. Acta Hydrol. Slovaca 2020, 20, 131-138. [CrossRef]

12. Ahn, S.R.; Jeong, J.H.; Kim, S.J. Assessing drought threats to agricultural water supplies under climate change by combining the SWAT and MODSIM models for the Geum River basin, South Korea. Hydrol. Sci. J. 2016, 61, 2740-2753. [CrossRef]

13. Cho, J.; Ko, G.; Kim, K.; Oh, C. Climate Change Impacts on Agricultural Drought with Consideration of Uncertainty in CMIP5 Scenarios. Irrig. Drain. 2016, 65, 7-15. [CrossRef]

14. Seung-Hwan, Y.; Jin-Yong, C.; Sang-Hyun, L.; Yun-Gyeong, O.; Koun, Y.D. Climate change impacts on water storage requirements of an agricultural reservoir considering changes in land use and rice growing season in Korea. Agric. Water Manag. 2013, 117, 43-54. [CrossRef] 
15. Lee, D.R.; Moon, J.W.; Lee, D.H.; Ahn, J.H. Development of water supply capacity index to monitor droughts in a reservoir. J. Korea Water Resour. 2006, 39, 199-241.

16. Nam, W.-H.; Kim, T.; Choi, J.-Y.; Lee, J.-J. Vulnerability Assessment of Water Supply in Agricultural Reservoir Utilizing Probability Distribution and Reliability Analysis Methods. J. Korean Soc. Agric. Eng. 2012, 54, 37-46. [CrossRef]

17. Jones, R.N. Analysing the risk of climate change using an irrigation demand model. Clim. Res. 2000, 14, 89-100. [CrossRef]

18. Döll, P. Impact of Climate Change and Variability on Irrigation Requirements: A Global Perspective. Clim. Chang. 2002, 54, 269-293. [CrossRef]

19. Fischer, G.; Tubiello, F.N.; Van Velthuizen, H.; Wiberg, D. Climate change impacts on irrigation water requirements: Effects of mitigation, 1990-2080. Technol. Forecast. Soc. Chang. 2007, 74, 1083-1107. [CrossRef]

20. Shahid, S. Impact of climate change on irrigation water demand of dry season Boro rice in northwest Bangladesh. Clim. Chang. 2010, 105, 433-453. [CrossRef]

21. Wada, Y.; Wisser, D.; Eisner, S.; Flörke, M.; Masaki, Y.; Portmann, F.T.; Stacke, T.; Tessler, Z.; Schewe, J.; Gerten, D.; et al. Multimodel projections and uncertainties of irrigation water demand under climate change. Geophys. Res. Lett. 2013, 40, 4626-4632. [CrossRef]

22. Ministry of Agriculture, Food and Rural Affairs (MAFRA). Statistical yearbook of land and water development for agriculture. In Agriculture in Korea; Korea Rural Community Corporation: Sejong, Korea, 2014.

23. Song, J.-H.; Her, Y.; Park, J.; Kang, M.-S. Exploring parsimonious daily rainfall-runoff model structure using the hyperbolic tangent function and Tank model. J. Hydrol. 2019, 574, 574-587. [CrossRef]

24. Burnash, R.J.C. The NWS river forecast system-catchment modeling. In Computer Models of Watershed Hydrology; Water Resources Publications: Highlands Ranch, CO, USA, 1995; pp. 311-366.

25. Sugawara, M. Tank Model, Computer Models of Watershed Hydrology; Water Resources Publications: Highlands Ranch, CO, USA, 1995; pp. 165-214.

26. Bergstrom, S. The HBV Model, Computer Models of Watershed Hydrology; Water Resources Publications: Highlands Ranch, CO, USA, 1995.

27. Nielsen, S.A.; Hansen, E. Numerical simulation of the rainfall-runoff process on a daily basis. Hydrol. Res. 1973, 4, 171-190. [CrossRef]

28. Havnø, K.; Madsen, M.N.; Dørge, J. MIKE 11-A generalized river modelling package. In Computer Models of Watershed Hydrology; Water Resources Publications: Highlands Ranch, CO, USA, 1995; pp. 733-782.

29. Kim, H.Y.; Park, S.W. Simulating daily inflow and release rates for irrigation reservoirs. J. Korean Soc. Agric. Eng. 1998, 30, 50-62.

30. Song, J.-H.; Kang, M.-S.; Song, I.; Jun, S.M. Water Balance in Irrigation Reservoirs Considering Flood Control and Irrigation Efficiency Variation. J. Irrig. Drain. Eng. 2016, 142, 04016003. [CrossRef]

31. Fukuda, T.; Jayadi, R.; Nakano, Y.; Kuroda, M. Application of complex tank model for evaluating performance of water operation in a Reused water irrigation system. J. Fac. Agric. Kyushu Univ. 1999, 44, 189-198.

32. Fumikazu, N.; Toshisuke, M.; Yoshio, H.; Hiroshi, T.; Kimihito, N. Evaluation of water resources by snow storage using water balance and tank model method in the Tedori River basin of Japan. Paddy Water Environ. 2011, 11, 113-121. [CrossRef]

33. Kuok, K.K.; Harun, S.; Chan, C.P. Investigation best number of tanks for hydrological tank model for rural catchment in humid region. J. Inst. Eng. 2011, 72, 1-11.

34. Basri, H. Development of Rainfall-runoff Modeling Using a Tank Model: Problems and Challenges in Province of Aceh, Indonesia. AIJST 2013, 2, 26-37.

35. Chen, R.-S.; Pi, L.-C.; Huang, Y.-H. Analysis of rainfall-runoff relation in paddy fields by diffusive tank model. Hydrol. Process. 2003, 17, 2541-2553. [CrossRef]

36. Nakano, Y.; Yoshida, T.; Inoue, T. A study on pesticide runoff from paddy fields to a river in rural region-2: Development and application of a mathematical model. Water Res. 2004, 38, 3023-3030. [CrossRef] [PubMed]

37. Chen, S.-K.; Chen, R.-S.; Yang, T.-Y. Application of a tank model to assess the flood-control function of a terraced paddy field. Hydrol. Sci. J. 2014, 59, 1020-1031. [CrossRef]

38. Ahmad, S.W. Tank Model Application for Runoff and Infiltration Analysis on Sub-Watersheds in Lalindu River in South East Sulawesi Indonesia. J. Phys. Conf. Ser. 2017, 846, 12019. [CrossRef] 
39. Hong, N.; Hama, T.; Suenaga, Y.; Aqili, S.W.; Huang, X.; Wei, Q.; Kawagoshi, Y. Application of a modified conceptual rainfall-runoff model to simulation of groundwater level in an undefined watershed. Sci. Total Environ. 2016, 541, 383-390. [CrossRef]

40. Jensen, M.E.; Burman, R.D.; Allen, R.G. Evapotranspiration and irrigation water requirements. ASCE 1990, $70,332$.

41. Jang, M.-W.; Choi, J.-Y.; Lee, J.-J. A spatial reasoning approach to estimating paddy rice water demand in Hwanghaenam-do, North Korea. Agric. Water Manag. 2007, 89, 185-198. [CrossRef]

42. Korea Water Resources Cooperation (KWRC). Dam Design Manual; Korea Water Resources Cooperation (KWRC): Dajeon, Korea, 2002.

43. Nam, W.-H.; Hong, E.-M.; Choi, J.-Y. Has climate change already affected the spatial distribution and temporal trends of reference evapotranspiration in South Korea? Agric. Water Manag. 2015, 150, 129-138. [CrossRef]

44. Peterson, D.F.; Keller, A.A. Effects of Climate Change on U.S. Irrigation. J. Irrig. Drain. Eng. 1990, 116, 194-210. [CrossRef]

45. Hatch, U.; Jagtap, S.; Jones, J.; Lamb, M. Potential Effects of Climate Change on Agricultural Water Use in the Southeast U.S. ${ }^{1}$. JAWRA J. Am. Water Resour. Assoc. 1999, 35, 1551-1561. [CrossRef]

46. Allen, R.G.; Pereira, L.S.; Raes, D.; Smith, M. Crop evapotranspiration: Guidelines for computing crop requirements. In FAO Irrigation and Drainage; Paper No. 56; Food and Agriculture Organization of the United Nations: Rome, Italy, 1998.

47. Kuo, S.-F.; Ho, S.-S.; Liu, C.-W. Estimation irrigation water requirements with derived crop coefficients for upland and paddy crops in ChiaNan Irrigation Association, Taiwan. Agric. Water Manag. 2006, 82, $433-451$. [CrossRef]

48. Yoo, S.-H.; Choi, J.-Y.; Jang, M.-W. Estimation of design water requirement using FAO Penman-Monteith and optimal probability distribution function in South Korea. Agric. Water Manag. 2008, 95, 845-853. [CrossRef]

49. Ministry of Agriculture and Forestry (MAF). Design Criteria of Land and Water; Ministry of Agriculture and Forestry (MAF): Sejong, Korea, 1998.

50. Doorenbos, J.; Kassam, A.H. Yield response to water. In FAO Irrigation and Drainage; Paper No. 33; Food and Agriculture Organization of the United Nations: Rome, Italy, 1979.

51. Yokoo, Y.; Kazama, S.; Sawamoto, M.; Nishimura, H. Regionalization of lumped water balance model parameters based on multiple regression. J. Hydrol. 2001, 246, 209-222. [CrossRef]

52. Ishihara, Y.; Kobatake, S. Runoff model for flood forecasting. In Bulletin of the Disaster Prevention Research Institute; Disaster Prevention Research Institute, Kyoto University: Kyoto, Japan, 1979; Volume 29, 260p.

53. Yevjevich, V. An Objective Approach to Definitions and Investigations of Continental Hydrologic Droughts; Hydrology Paper No. 23; Colorado State University: Fort Collins, CO, USA, 1967.

54. Guerrero-Salazar, P.L.A.; Yevjevich, V.M. Analysis of Drought Characteristics by the Theory of Runs; Hydrology papers No. 80; Colorado State University: Fort Collins, CO, USA, 1975.

55. Moyé, L.A.; Kapadia, A.S.; Cech, I.M.; Hardy, R.J. The theory of runs with applications to drought prediction. J. Hydrol. 1998, 103, 127-137. [CrossRef]

56. Cancelliere, A.; Salas, J. Drought length properties for periodic-stochastic hydrologic data. Water Resour. Res. 2004, 40. [CrossRef]

57. Chang, J.; Li, Y.; Wang, Y.; Yuan, M. Copula-based drought risk assessment combined with an integrated index in the Wei River Basin, China. J. Hydrol. 2016, 540, 824-834. [CrossRef]

58. Yang, J.; Chang, J.; Wang, Y.; Li, Y.; Hu, H.; Chen, Y.; Huang, Q.; Yao, J. Comprehensive drought characteristics analysis based on a nonlinear multivariate drought index. J. Hydrol. 2018, 557, 651-667. [CrossRef]

59. Cannon, A.J.; Sobie, S.R.; Murdock, T.Q. Bias Correction of GCM Precipitation by Quantile Mapping: How Well Do Methods Preserve Changes in Quantiles and Extremes? J. Clim. 2015, 28, 6938-6959. [CrossRef]

60. Eum, H.-I.; Cannon, A.J. Intercomparision of projected changes in climate extremes for south Korea: Application of trend preserving statistical downscaling methods to the CMIP5 Ensemble. Int. J. Climatol. 2017, 37, 3381-3397. [CrossRef]

(C) 2020 by the authors. Licensee MDPI, Basel, Switzerland. This article is an open access article distributed under the terms and conditions of the Creative Commons Attribution (CC BY) license (http://creativecommons.org/licenses/by/4.0/). 